\author{
UNIVERSIDADE DE SÃO PAULO \\ ESCOLA DE ENFERMAGEM DE RIBEIRÃO PRETO
}

LEANDRA TEREZINHA RONCOLATO DA SILVA

AVALIAÇÃO DA QUALIDADE DA ASSISTÊNCIA À SAÚDE QUANTO ÀS MEDIDAS DE PREVENÇÃO E CONTROLE DE PNEUMONIA ASSOCIADA À VENTILAÇÃO MECÂNICA

RIBEIRÃO PRETO

2010 
LEANDRA TEREZINHA RONCOLATO DA SILVA

\section{AVALIAÇÃO DA QUALIDADE DA ASSISTÊNCIA À SAÚDE QUANTO ÀS MEDIDAS DE PREVENÇÃO E CONTROLE DE PNEUMONIA ASSOCIADA À VENTILAÇÃO MECÂNICA}

Dissertação apresentada à Escola de Enfermagem de Ribeirão Preto da Universidade de São Paulo, para obtenção do título de Mestre em Ciências, Programa de Pós-Graduação Enfermagem Fundamental.

Linha de pesquisa: Dinâmica da organização dos serviços de saúde e de enfermagem.

Orientadora: Prof ${ }^{a}$. Drª . Ana Maria Laus

RIBEIRÃO PRETO 
Autorizo a reprodução e divulgação total ou parcial deste trabalho, por qualquer meio convencional ou eletrônico, para fins de estudo e pesquisa, desde que citada a fonte.

FICHA CATALOGRÁFICA

SILVA, LEANDRA TEREZINHA RONCOLATO DA

Avaliação da qualidade da assistência à saúde quanto às medidas de prevenção e controle de pneumonia associada à ventilação mecânica. Ribeirão Preto, 2010.

98p. : il. ; $30 \mathrm{~cm}$

Dissertação (Mestrado) Programa de Pós-Graduação em Enfermagem Fundamental da Escola de Enfermagem de Ribeirão Preto da Universidade de São Paulo.

Orientadora: Laus, Ana Maria

1. Indicadores de qualidade em assistência à saúde. 2. Avaliação em saúde.

3. Pneumonia associada à ventilação mecânica. 4. Enfermagem. 
FOLHA DE APROVAÇÃO

Leandra Terezinha Roncolato da Silva

Avaliação da qualidade da assistência à saúde quanto às medidas de prevenção e controle de pneumonia associada à ventilação mecânica.

Dissertação apresentada à Escola de Enfermagem de Ribeirão Preto da Universidade de São Paulo, para obtenção do título Mestre em Ciências, Programa Enfermagem Fundamental.

Aprovado em:

Banca Examinadora

Prof. Dr.:

Instituição:

Assinatura:

Prof. Dr.:

Instituição:

Assinatura:

Prof. Dr.:

Instituição: Assinatura: 


\section{DedicatóRIA}

Àqueles que, incansáveis, dedicam inestimados cuidados aos que dependem de suas mãos para sobreviver. 


\section{AgRADECIMENTOS}

A Deus, por me iluminar, dar força e perseverança para realização deste trabalho.

Ao Rafael, meи esposo, que sempre esteve ao meu lado acreditando em meus sonhos profissionais. Pelo amor, carinho, companheirismo, paciência e compreensão de minha ausência no processo de elaboração deste trabalho.

Aos meus pais, Terezinha e José, pelos conselhos valiosos e por sempre estarem ao meu lado.

A toda minha família, pelo apoio, carinho e compreensão em todos os momentos.

À Prof ${ }^{a}$ Dr $^{a}$ Clarice Aparecida Ferraz, pelo apoio e confiança.

À minha orientadora, $\operatorname{Prof}^{a} \operatorname{Dr}^{a}$ Ana Maria Laus, pelos valiosos ensinamentos ao longo desta caminhada. Obrigada pela sabedoria, paciência e apoio e por acreditar em meu trabalho.

\section{À Prof ${ }^{a}$ Dr $^{a}$ Silvia Rita Marin da Silva Canini e à Enfermeira Dr ${ }^{a}$ Miyeko} Hayashida, pelas sugestões fundamentais no aperfeiçoamento do estudo, disponibilidade e atenção despendida no decorrer desta trajetória.

Às enfermeiras e amigas da UTI, local de realização deste estudo. Em especial à Aline dos Santos, Bianca C. Ciccone Giacon e Cristane Motta Machado, pelo convívio, apoio, conforto nos momentos difíceis e dedicação durante a coleta de dados desta pesquisa. 
A grandeza não consiste em receber honras, mas em merecê-las...

Aristóteles 


\section{RESUMO}

SILVA, LEANDRA TEREZINHA RONCOLATO DA. Avaliação da qualidade da assistência à saúde quanto às medidas de prevenção e controle de pneumonia associada à ventilação mecânica. 2010. 98f. Dissertação (Mestrado) - Escola de Enfermagem de Ribeirão Preto, Universidade de São Paulo, Ribeirão Preto, 2010.

Os serviços de saúde vêm desenvolvendo programas e ações visando a qualificação de seus processos de trabalho com intuito de reduzir, eliminar e prevenir deficiências da qualidade e que também atendam às necessidades e expectativas dos usuários. Diferentes estratégias de avaliação das práticas em saúde têm sido adotadas, permitindo a identificação das condições em que as práticas assistenciais são executadas. As infecções hospitalares constituem risco significativo à saúde dos usuários e, dentre estas, a pneumonia (PNM) assume particular importância, dada a prevalência e mortalidade a ela associadas, especialmente quando acomete pacientes graves internados em unidades de terapia intensiva (UTI). Para avaliação dos processos de trabalho, a literatura recomenda a utilização de indicadores que avaliem não só a estrutura, como também o processo e o resultado. Assim, este estudo objetivou avaliar a qualidade da assistência à saúde prestada em uma UTI, quanto ao uso das medidas de prevenção e controle de PNM em pacientes de alto risco submetidos à ventilação mecânica. Trata-se de um estudo descritivo exploratório, com abordagem quantitativa, realizado na UTI adulto de um hospital público de ensino de grande porte e nível terciário. Os sujeitos da pesquisa foram os pacientes internados na unidade sob assistência ventilatória invasiva com rebaixamento de consciência e/ou nutrição por sondas digestivas. Os dados foram coletados diariamente nos três turnos de trabalho utilizando o Indicador de Avaliação da Adesão às Medidas de Prevenção e Controle de Pneumonia em Pacientes de Alto Risco (IRPR) que monitora a aplicação de medidas de controle e prevenção de pneumonia hospitalar, a saber: decúbito elevado (entre 30 e $45^{\circ}$ ), fisioterapia respiratória, utilização de soluções estéreis nos equipamentos de terapia respiratória e adesão à rotina de troca dos inaladores estabelecida na instituição. Participaram do estudo, 38 pacientes, sendo 26 (68,42\%) do sexo masculino e $12(31,58 \%)$ do sexo feminino, com idades entre 19 e 82 anos e tempo de internação na UTI de 1 a 28 dias. Destes pacientes, 19 receberam alta, 3 (7,89\%) permaneceram internados e 16 $(42,10 \%)$ evoluíram para óbito. Foram realizadas 839 observações, relacionadas às medidas de prevenção e controle de PAVM conforme indicador IRPR. A conformidade geral a todas as medidas de prevenção e controle de PAVM correspondeu a 26,94\%. A manutenção da cabeceira elevada e o atendimento de fisioterapia foram as medidas que mais influenciaram negativamente na obtenção dessa conformidade geral. Observou-se nos prontuários médicos que 13 (34,21\%) pacientes desenvolveram PNM durante a internação. Foram calculados os índices de conformidade e não conformidade geral e de cada medida específica de prevenção e controle de PAVM para estes pacientes, com resultados semelhantes. Conclui-se que a conformidade alcançada nesta investigação não foi satisfatória (26,94\%), embora algumas medidas isoladas que compõem o indicador IRPR tenha alcançado índices próximos a 100\%. Este estudo possibilitou identificar a não adesão a determinadas práticas, embora instituídas na instituição investigada. Espera-se que a divulgação dos resultados propicie a adoção de novas estratégias educativas para equipe de saúde, visando desenvolver ações de melhoria contínua para práticas assistenciais.

Palavras-chave: Indicadores de qualidade em assistência à saúde. Avaliação em saúde. Pneumonia associada à ventilação mecânica. Enfermagem. 


\begin{abstract}
SILVA, LEANDRA TEREZINHA RONCOLATO DA. Evaluation of quality of health care regarding the measures of prevention and control of ventilator-associated pneumonia. 2010. 98f. Master's Thesis - University of São Paulo at Ribeirão Preto College of Nursing, Ribeirão Preto, 2010.
\end{abstract}

The health services have been developing programs and actions aiming at the qualification their process of work with intent to reduce, to eliminate and to prevent deficiencies of the quality and that also meet the needs and expectations of users. Different strategies of evaluation of the practices in health have been adopted, allowing the identification of the conditions under which care practices are executed. The hospital infections constitute significant risk the health of the users and among these, the pneumonia (PNM) assumes private importance, given the prevalence and mortality it associated, especially when to assault patient serious interned in units of intensive therapy (UTI). For evaluation of the work processes, the literature recommends the use of pointers that not only evaluate the structure, as well as the process and the result. Thus, this study it objectified to evaluate the quality of the assistance to the health given in a UTI, how much to the use of the measures of prevention and control of PNM in patients of high risk submitted to the ventilation mechanics. This is a descriptive exploratory study, with quantitative boarding, carried through in the adult UTI of a public hospital of education of great transport and tertiary level. The study subjects were patients interned in the unit under invasive ventilators support with degradation of conscience and/or nutrition for digestive sounding leads. The data had been collected daily in the three turns of work using the Pointer of Evaluation of the Adhesion to the Measures of Prevention and Control of Pneumonia in at righ risk (IRPR) that monitors the application of measures of control and prevention of hospital pneumonia, namely: high decubitus (between 30 and 45), respiratory therapy, use of barren solutions in the equipment of respiratory therapy and adhesion to the routine of exchange of inhalers established in the institution. Participated in the study, 38 patients, being $26(68.42 \%)$ of masculine sex and $12(31.58 \%)$ of the feminine sex, with ages between 19 and 82 years and time of internment in the UTI of 1- 28 days. From these patients, 19 they had 19 received high, $3(7.89 \%)$ had remained interned and $16(42.10 \%)$ had evolved for death. 839 comments, related to the measures of prevention and control of PAVM as indicating IRPR had been carried through. General conformity to all the measures of prevention and control of PAVM corresponded $26.94 \%$. The maintenance of the high headboard and the attendance of therapy had been the measures that had more influenced negative in the attainment of this general conformity. It was observed in the medical handbooks that 13 (34.21\%) patient ones had developed PNM during the internment. The indices of conformity and not general conformity and each specific measure of prevention and control of PAVM for these patients had been calculated, with similar results. One even so concludes that the conformity reached in this inquiry was not satisfactory (26.94\%), some isolated measures that compose pointer IRPR have reached next indices the $100 \%$. This study identified not adherence to certain practices, through established in the institution studied. It is hoped that the dissemination of results conducive to the adoption of new educational strategies for health staff in order to develop actions for continuous improvement to health care practices.

Keywords: Quality indicators, Health care; Pneumonia, ventilator-associated; Nursing; Health evaluation. 


\section{RESUMEN}

SILVA, LEANDRA TEREZINHA RONCOLATO DA. Evaluación de la calidad de la asistencia a salud cuanto a las medidas de prevención y control de neumonía asociada a la ventilación mecánica. 2010. 98f. Dissertación (Maestría) - Escuela de Enfemería de Ribeirão Preto, Universidad de São Paulo, Ribeirão Preto, 2010.

Los servicios de salud desarrollan programas y acciones buscando la calificación de sus procesos de trabajo con el fin de reducir, eliminar y prevenir deficiencias de la calidad, además de atender a las necesidades y expectativas de los usuarios. Diferentes estrategias de evaluación de las prácticas en salud han sido adoptadas, lo que permite la identificación de las condiciones en las que las prácticas de atención son ejecutadas. Las infecciones hospitalarias son un riesgo significativo a la salud de los usuarios y entre ellas, la neumonía (NM) es de particular importancia, dada la prevalencia y mortalidad asociada a ella, especialmente cuando se trata de enfermos graves hospitalizados en unidades de terapia intensiva $(\mathrm{UCl})$. Para la evaluación de los procesos de trabajo, la literatura recomienda el uso de indicadores que evalúen no sólo la estructura, sino también el proceso y el resultado. Este estudio tuvo como objetivo evaluar la calidad de la atención a la salud prestada en una UTI, en cuanto a la utilización de medidas de prevención y control de NM en pacientes de alto riesgo sometidos a ventilación mecánica. Esta investigación descriptiva, exploratoria y cuantitativa fue realizada en la UTI adulto de un hospital público de enseñanza de gran porte y nivel terciario. Los sujetos del estudio fueron todos los pacientes internados en la unidad en atención ventilatoria invasiva con disminución del nivel de consciencia y/o nutrición por sondas digestivas. Los datos fueron recolectados diariamente en los tres turnos de trabajo utilizando el Indicador de Evaluación de la Adhesión a las Medidas de Prevención y Control de Neumonía en Pacientes de Alto Riesgo (IRPR) que monitoriza la aplicación de medidas de control y prevención de neumonía hospitalaria, a saber: decúbito elevado (entre 30 y 459 , fisioterapia respiratoria, utilización de soluciones estériles en los equipamientos de terapia respiratoria y adhesión a la rutina de cambio de inhaladores establecida en la institución. Participaron del estudio 38 pacientes, siendo $26(68,42 \%)$ del sexo masculino y 12 $(31,58 \%)$ del sexo femenino, con edades entre 19 y 82 años y tiempo de internación en la UTI de 1 a 28 días. De estos pacientes, 19 recibieron el alta, $3(7,89 \%)$ permanecieron internados y $16(42,10 \%)$ fallecieron. Fueron realizados 839 observaciones, relacionadas a las medidas de prevención y control de NAVM (neumonía asociada a la ventilación mecánica) según indicador IRPR. La conformidad general a todas las medidas de prevención y control de NAVM correspondió al 26,94\%. La manutención de la cabecera elevada y la atención de fisioterapia fueron las medidas que más influyeron negativamente en la obtención de esa conformidad general. Se observó en los registros médicos que 13 $(34,21 \%)$ pacientes desarrollaron NM durante la internación. Fueron calculados los índices de conformidad y no conformidad general y de cada medida específica de prevención y control de NAVM para estos pacientes, con resultados similares. Se concluye que la conformidad obtenida en esta investigación no ha sido satisfactoria (26,94\%), aunque algunas medidas aisladas que componen el indicador IRPR tengan alcanzado índices cercanos al $100 \%$. Este estudio posibilitó identificar la no adhesión a determinadas prácticas, aunque establecidas en la institución investigada. Se espera que la divulgación de los resultados favorezca la adopción de nuevas estrategias educativas para el equipo de salud, buscando desarrollar acciones de mejoría continua para las prácticas de atención.

Palabras-clave: Indicadores de calidad de la atención de salud. Evaluación en salud. Neumonia asociada al ventilador. Enfermería. 


\section{LISTA DE QUADRO}

Quadro 1 - Fontes de informação e critérios para avaliação das medidas específicas de prevenção e controle de PAVM (IRRP). Ribeirão Preto, 2010............................................... 


\section{LISTA DE TABELAS}

Tabela 1 - Distribuição dos pacientes com ventilação mecânica de um hospital público, segundo as variáveis idade e tempo de permanência na Unidade de Terapia Intensiva (UTI), por sexo,

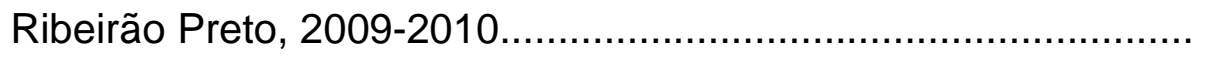

Tabela 2 - Distribuição dos pacientes com ventilação mecânica de um hospital público, segundo as unidades de internação prévia e pós-Unidade de Terapia Intensiva (UTI), Ribeirão Preto, 20092010.

Tabela 3 - Distribuição de pacientes segundo média do valor do APACHE Il e do risco de óbito e desfecho do caso, Ribeirão Preto, 20092010

Tabela 4 - Distribuição das observações dos pacientes de um hospital público, com respectivos percentuais de conformidade geral, por turno de trabalho, das medidas específicas de prevenção e controle de pneumonia associada à ventilação mecânica, Ribeirão Preto, 2009-2010.

Tabela 5- Total de observações e índices de conformidade e não conformidade de cada medida específica de controle e prevenção de pneumonia associada à ventilação mecânica, por turno de trabalho, Ribeirão Preto, 2009-2010.

Tabela 6 - Índices de não conformidade de cada medida específica de controle e prevenção de pneumonia associada à ventilação mecânica, segundo o turno de trabalho, Ribeirão Preto, 20092010

Tabela 7 - Distribuição dos pacientes com ventilação mecânica de um hospital público, por sexo, segundo a presença de pneumonia associada à ventilação mecânica, Ribeirão Preto, 2009-2010......

Tabela 8 - Pacientes com ventilação mecânica que apresentaram pneumonia segundo tempo de internação e tempo de aparecimento da morbidade, Ribeirão Preto, 2009-2010. 
Tabela 9- Pacientes com ventilação mecânica que apresentaram pneumonia segundo os índices de conformidade geral e prévia à morbidade, valor do APACHE II, risco de óbito e desfecho do caso, Ribeirão Preto, 2009-2010.

Tabela 10 - Índices da conformidade geral e por turno de trabalho das medidas específicas de prevenção e controle de pneumonia associada à ventilação mecânica para os pacientes que desenvolveram pneumonia ( $n=13$ ), Ribeirão Preto, 2009-2010....

Tabela 11- Total de observações e índices de conformidade e não conformidade de cada medida específica de controle e prevenção de pneumonia associada à ventilação mecânica para os pacientes que desenvolveram pneumonia $(n=13)$ segundo o turno de trabalho, Ribeirão Preto, 2009-2010................................ 


\section{LISTA DE ABREVIATURAS E SIGLAS}

$\begin{array}{ll}\text { SUS } & \text { Sistema Único de Saúde } \\ \text { OMS } & \text { Organização Mundial de Saúde } \\ \text { FNQ } & \text { Fundação Nacional da Qualidade } \\ \text { JCAHO } & \text { Joint Comission on Acreditation of Healthcare Organization } \\ \text { ANVISA } & \text { Agência Nacional de Vigilância Sanitária } \\ \text { UTI } & \text { Unidade de Terapia Intensiva } \\ \text { IH } & \text { Infecção Hospitalar } \\ \text { VM } & \text { Ventilação Mecânica } \\ \text { PNM } & \text { Pneumonia }\end{array}$

PAVM Pneumonia Associada à Ventilação Mecânica

PAH Pneumonia Adquirida no Hospital

SBPT Sociedade Brasileira de Pneumologia e Tisiologia

EUA Estados Unidos da América

DPOC Doença Pulmonar Obstrutiva Crônica

CS Controle e prevenção de infecção da corrente sanguínea associada a cateter vascular central de curta permanência

SC Controle e prevenção de infecção do sítio cirúrgico

IR Controle e prevenção de infecção respiratória

IU Controle e prevenção de infecção do trato urinário associada a cateter vesical

IS Indicação à aplicação de normas de isolamento e precauções

HM Higiene das mãos

APACHE II Acute Physiology and Chronic Health Evaluation II

USP Universidade de São Paulo

DRS XIII Divisão Regional de Saúde XIII

SAME Serviço de Arquivo Médico

COT Cânula Orotraqueal

TCLE Termo de Consentimento Livre e Esclarecido

IRPR Indicador de avaliação de adesão às medidas de prevenção e controle de Pneumonia em pacientes de alto risco

SNG/SNE Sonda Nasogástrica/Sonda Nasoentérica 

A Atende
NA Não atende
SA Sem aplicação
HCFMRP Hospital das Clínicas da Faculdade de Medicina de Ribeirão Preto
FMRP Faculdade de Medicina de Ribeirão Preto
CCIH Comissão de Controle de Infecção Hospitalar
IASS Infecções Adquiridas nos Serviços de Saúde
OD Observação Direta
CDC Centers for Disease Control and Prevention Guidelines 


\section{SUMÁRIO}

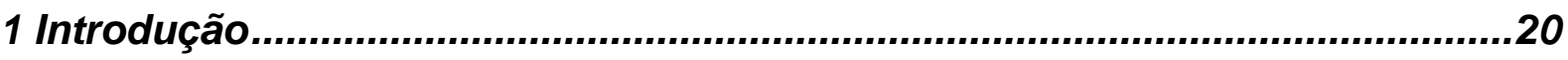

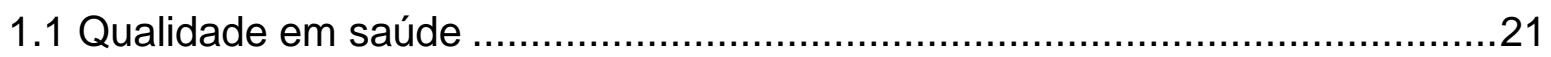

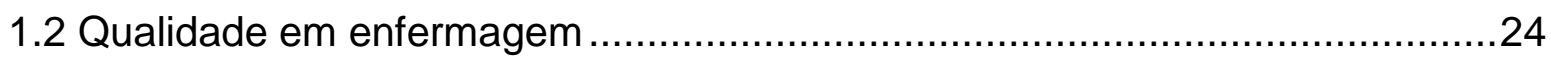

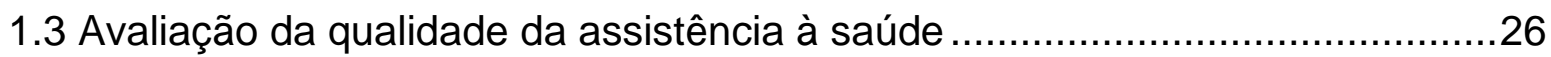

1.3.2 Indicadores clínicos de avaliação da assistência à saúde............................31

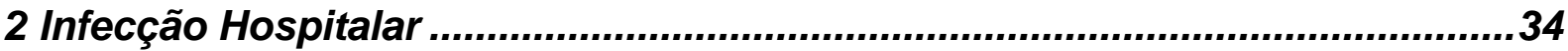

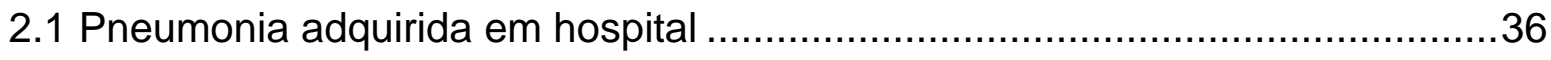

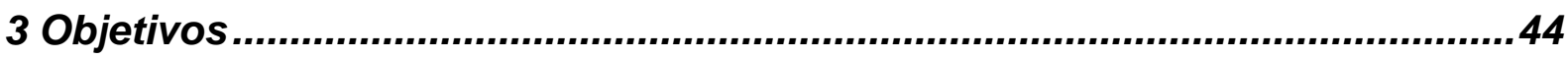

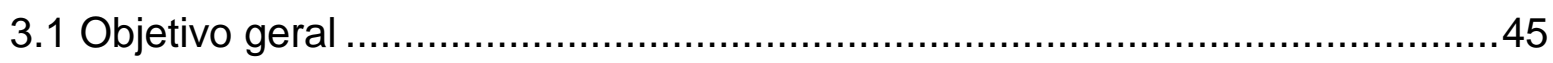

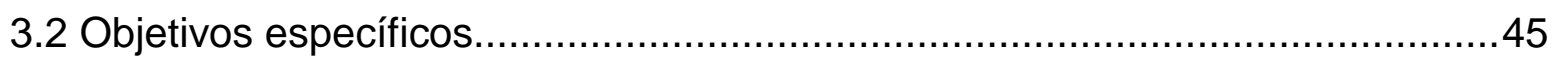

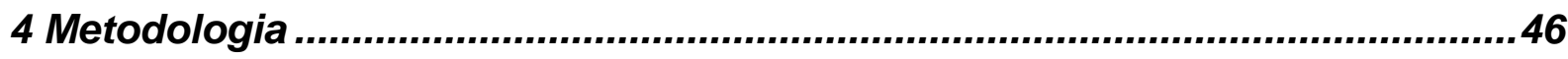

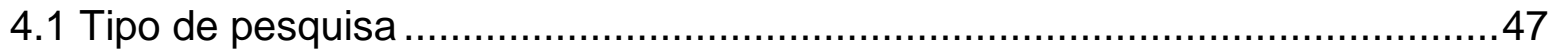

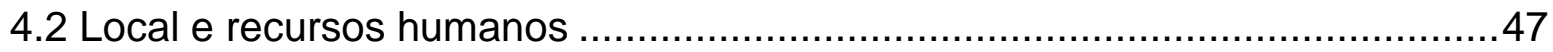

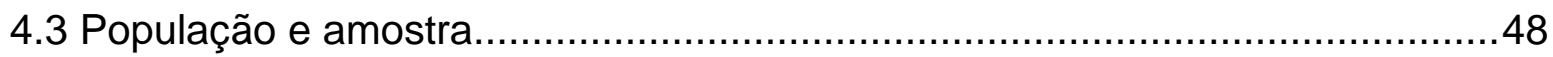

4.4 Instrumentos e procedimentos de coleta de dados ......................................49

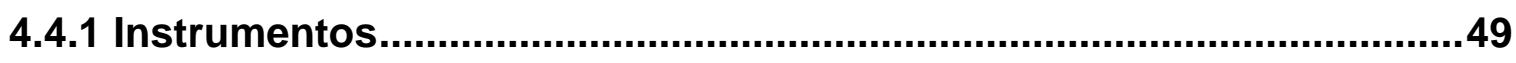

4.4.2 Procedimento de coleta dos dados .....................................................53

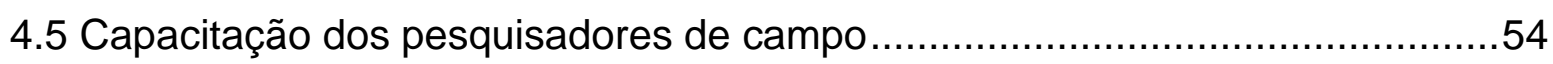

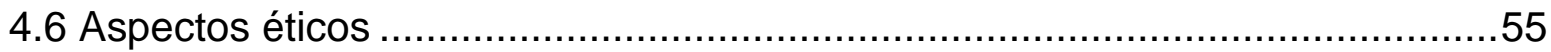

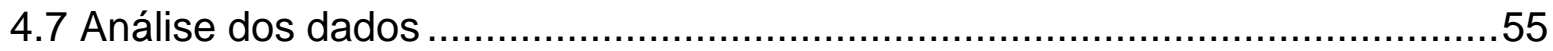

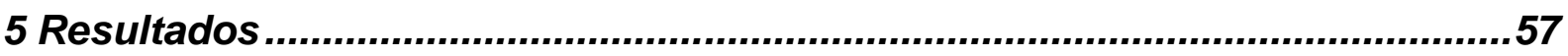

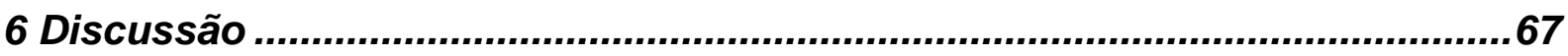

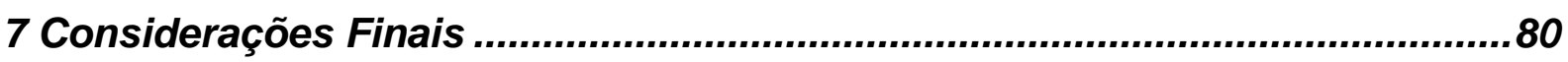

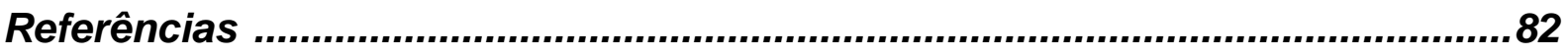

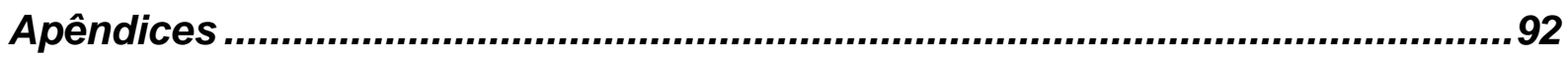

Anexos 
Apresentação 
A enfermagem é fundamental no âmbito da saúde, valorizada por seu conhecimento especializado, suas habilidades no cuidado, visando um melhor padrão de saúde da população e garantir-Ihe uma assistência segura, efetiva e de qualidade (BORK, 2004).

Ao inserir-se no mercado de trabalho, o enfermeiro percebe a real complexidade deste cuidado e o quanto é difícil garantir uma assistência de enfermagem qualificada, uma vez que não depende apenas de si próprio, mas também dos recursos humanos, materiais e estruturais disponíveis, além do comprometimento da equipe com o trabalho e o paciente.

No início da minha carreira profissional, trabalhei em um hospital privado de pequeno porte, que também realizava atendimento aos usuários do Sistema Único de Saúde (SUS), em um município do estado de São Paulo, no qual vivenciei as dificuldades da prática profissional diante da escassez de recursos humanos e a necessidade exigida pela gerência administrativa sobre qualidade dos cuidados de enfermagem prestados. Em várias situações me deparei com a impossibilidade de garantir uma assistência qualificada, mas percebia que a equipe se desdobrava para realizar as diferentes intervenções necessárias.

Ao ingressar como enfermeira assistencial em um hospital de ensino de nível terciário, em Ribeirão Preto - SP, e ser direcionada para exercer minhas atividades em uma Unidade de Terapia Intensiva (UTI), vivenciei mais proximamente as demandas requeridas por pacientes críticos, exigindo cuidados complexos, terapia de alto custo e demanda de cuidados de enfermagem.

Essa vivência quanto à dinâmica desta unidade não só nos aspectos assistenciais, mas também nas especificidades de organização que incluíam as relativas ao relacionamento entre as diferentes equipes que ali atuavam, ampliaram meu interesse pela área, pois percebia que o enfermeiro era peça fundamental para o desenvolvimento da qualidade da assistência.

A complexidade dos cuidados, a variedade de procedimentos invasivos que são realizados pela equipe de saúde, diariamente, na UTI,e a questão do controle da de Infecção Hospitalar $(\mathrm{IH})$ despertaram meu interesse em investigar com maior profundidade a qualidade destes cuidados. A preocupação quanto a este aspecto tem sido alvo de inúmeros estudos, os quais buscam propiciar subsídios para qualificação da assistência aos pacientes que requerem cuidados intensivos. 
Uma atenção especial me direcionou para um olhar mais apurado sobre a questão da ventilação mecânica (VM) a que eram submetidos os pacientes, visto que a associação de pneumonia (PNM) a este procedimento é uma das infecções nosocomiais mais frequentes e de maior morbi-mortalidade em pacientes intubados ou traqueostomizados submetidos a esta intervenção em unidades de cuidados intensivos ou semi-intensivos.

A prevenção da pneumonia associada à ventilação mecânica (PAVM) envolve procedimentos técnicos realizados pela equipe multidisciplinar, o que torna difícil a definição da responsabilidade por este cuidado. Porém, a adoção de medidas de prevenção e controle da PAVM, pode contribuir para a qualidade da assistência.

Diante do exposto, julgou-se oportuno a realização do presente estudo. 


\subsection{Qualidade em saúde}

A qualidade é visualizada, no mundo contemporâneo, como uma forma de gerenciamento que, quando implantada, melhorará de modo contínuo o desempenho organizacional. Os setores de prestação de serviços de saúde, públicos ou privados, não estão fora deste contexto.

A qualidade na saúde vem sofrendo alterações ao longo dos anos e um novo paradigma em relação ao gerenciamento das instituições reconhece que a qualidade não é só um atributo de um produto ou serviço, mas é também a medida de um relacionamento entre todos envolvidos no processo.

O uso de metodologias da qualidade torna-se particularmente valioso quando se considera a situação atual da gestão de serviços de saúde no país, ou seja, a escassa utilização de planejamento estratégico, a inexistência de um sistema de informações confiáveis, a ausência de um sistema de gestão fundamentado na melhoria do processo e centrado em resultados, a carência de indicadores de desempenho e de qualidade, enfim, a inexistência de uma cultura de qualidade voltada para a qualificação da estrutura organizacional e, principalmente, para a satisfação dos seus clientes e usuários (MALIK, 1996).

Atualmente, verifica-se nos serviços de saúde que o conceito de qualidade vem sendo bastante difundido e discutido em organizações comprometidas com o desenvolvimento de programas e ações que atendam às necessidades e expectativas dos usuários. O movimento da qualidade iniciado no setor industrial e expandindo-se para o setor de serviços, rapidamente foi adotado pelas instituições de saúde, que incorporaram as teorias básicas de controle e melhoria da qualidade. Nesta direção, ações de melhoria do processo de produção das ações de enfermagem também têm ganhado espaço e atenção dos gerentes dos serviços e de pesquisadores (NONINO, 2006).

A qualidade dos produtos é preocupação desde que o processo produtivo era manual, quando os consumidores confiavam nos produtos dos artesãos que, muitas vezes, executavam o trabalho em grupo almejando um produto final melhor. No entanto, o tema qualidade ganhou destaque maior a partir da Revolução Industrial quando a produção de bens de consumo passou a requerer padronização dos produtos e utilização de instrumentos de avaliação (NONINO, 2006). 
No Brasil, o despertar pela qualidade em saúde iniciou-se nos anos 80 decorrente de múltiplas razões, como o aumento da demanda por cuidados de saúde, custos crescentes para manutenção dos serviços, limitados recursos disponíveis, conscientização dos direitos pelos usuários que se tornam cada vez mais exigentes, reivindicações dos profissionais de saúde e dos governos (ANTUNES; TREVIZAN, 2000; ADAMI; YOSHITOME, 2003; HADDAD, 2004).

Nas últimas décadas, as instituições de saúde têm se preocupado com a qualidade dos serviços, buscando o desenvolvimento de processos que reduzam custos, permitam excelência nas ações, aumentem a produtividade e garantam a segurança e satisfação do cliente.

Neste cenário, toda instituição que tem como missão assistir ao ser humano, preocupa-se com a melhoria constante do atendimento, buscando harmonia entre as áreas administrativa, tecnológica, econômica, assistencial, de ensino e de pesquisa (KURCGANT; TRONCHIN; MELLEIRO, 2006).

Frente a este processo, verifica-se o surgimento de programas de gestão pela qualidade, definidos como sistemas estruturados com o objetivo de atender e superar as necessidades e expectativas dos clientes, por meio do controle e aperfeiçoamento contínuo do seu processo de trabalho no sentido de reduzir, eliminar e prevenir deficiências da qualidade (MOURA, 2000; NONINO, 2006; PAIVA, 2006).

Entretanto faz-se necessário apontar que o conceito de qualidade em saúde é subjetivo e difícil de ser definido. Para Fernandes et al (2000), apesar de seu uso generalizado, ele continua vago e polêmico. Conceituar qualidade traz muitas implicações paradigmáticas que vão desde o saber científico até o senso comum (RÊGO; PORTO, 2005).

Qualidade é definida como um conjunto de atributos que inclui a excelência profissional, os recursos disponíveis, um mínimo risco aos usuários, a satisfação dos clientes, considerando os valores sociais existentes (ORGANIZAÇÃO MUNDIAL DE SAÚDE - OMS, 1981; DONABEDIAN, 1992a).

Segundo o Prêmio Nacional de Gestão em Saúde, qualidade consiste na totalidade de características de uma atividade ou processo, produto, organização, ou uma combinação destes, que confere à instituição a capacidade de satisfazer as necessidades explícitas e implícitas dos clientes e demais partes interessadas (FUNDAÇÃO NACIONAL DA QUALIDADE - FNQ, 2006). 
Donabedian, que pesquisou qualidade por mais de 20 anos, apresentou, em 1984, um conceito unificado de qualidade no qual expressa que o melhor cuidado é o que considera o balanço de ganhos e perdas esperados que acompanham todas as etapas do processo do cuidado, maximizando o bem-estar do paciente.

Portanto, a assistência de qualidade implica em aumentar as probabilidades de êxito e reduzir aquelas consideradas como indesejáveis (ADAMI; MARANHÃO, 1995).

A qualidade deve ser enfatizada nos serviços de saúde, principalmente, porque o produto/serviço é consumido durante a produção/execução, não sendo possível separar produtos defeituosos (SILVA 1 , 1996 apud MOTA; MELLEIRO; TRONCHIN, 2007).

Assim sendo, as ações de saúde produzidas em diferentes serviços, são resultantes da articulação e interdependência do trabalho de diferentes profissionais, com distintos graus de qualificação, nível educacional, além de motivações e interesses também diferenciados, o que reflete no desempenho das instituições.

O gerenciamento realizado por meio de programas de qualidade, utiliza conceitos de administração, envolvimento e comprometimento de pessoas, instrumentos de medida e de avaliação do trabalho. Além disso, busca a redução de desperdícios pela utilização adequada dos recursos e 0 atendimento das necessidades dos clientes pela melhoria dos processos de trabalho (SILVA; PINHEIRO, 2001).

Um programa de qualidade deve assegurar ao usuário o grau específico de excelência ou, conforme uma tendência mais recente, melhorar a qualidade de maneira contínua. Um programa assim comporta dois processos: o primeiro inclui a mensuração e avaliação de diversos aspectos da estrutura organizacional, da execução dos cuidados ou de seus resultados e o segundo comporta a planificação de estratégias para sua melhoria (DREYER,1997).

Portanto, o desenvolvimento de programas desta natureza é uma necessidade em termos não só de eficiência, mas se constitui numa obrigação do ponto de vista ético e moral. Toda instituição de saúde, dada a sua missão essencial a favor do ser humano, deve se preocupar com a melhoria permanente, de tal forma

\footnotetext{
${ }^{1}$ SILVA, V.E.F. Qualidade nas instituições de saúde e a prática da enfermagem. São Paulo: Departamento de Orientação Profissional - Escola de Enfermagem, Universidade de São Paulo, 1996. 13p.
} 
que consiga uma integração harmônica das áreas médicas, tecnológicas, administrativas, econômicas, assistenciais, de docência e pesquisa (BRASIL, 1999).

\subsection{Qualidade em enfermagem}

A questão da qualidade na Enfermagem na era moderna iniciou-se com Florence Nightingale, no começo do século XX, que propôs regras de conduta e ação para os profissionais e implantou o primeiro modelo de melhoria contínua da qualidade em saúde, baseando-se em dados estatísticos. Além disso, coligiu dados de mortalidade e morbidade hospitalar, identificando padrões de assistência (MATSUDA; ÉVORA; BOAN, 2000; ZANON, 2001; MALIK, 2004; ADAMI, YOSHITOME, 2003).

Ainda, conforme a literatura, foram as enfermeiras, na linha de Nightingale, que iniciaram a organização dos conhecimentos de enfermagem, preocupando-se com as descrições detalhadas de técnicas e procedimentos, visando o controle de qualidade. Sempre existiu um controle informal da qualidade da assistência na enfermagem, representado pela preocupação secular das enfermeiras em seguir os procedimentos à risca, considerando que com isso, garantir-se-iam os resultados desejados (Cianciarullo, 1997).

Considerando que a equipe de enfermagem representa o maior contingente de profissionais da saúde em contato direto com o paciente e com maior intensidade e maior frequência, geralmente o julgamento sobre as instituições de saúde, do ponto de vista dos usuários, baseia-se na qualidade dos serviços de enfermagem (BADDER, 1998).

Para Cianciarullo (1991), o conjunto de conhecimentos e habilidades específicas integrado a um sistema de valores e crenças dos enfermeiros é um forte determinante da qualidade da assistência ou do cuidado de enfermagem prestado ao indivíduo, à família e à comunidade.

Portanto, a qualidade da assistência de enfermagem dependerá de uma relação adequada entre enfermeiro e paciente, de padronização dos procedimentos e de treinamento dos profissionais (ZANON, 2001).

Nesta perspectiva, a busca pela melhoria contínua da qualidade da assistência de enfermagem requer implementação de ações e elaboração de 
instrumentos, pelos enfermeiros, que possibilitem avaliar de modo sistemático os níveis de qualidade dos cuidados prestados (FONSECA et al, 2005).

Ao prestar uma assistência de enfermagem com qualidade, o enfermeiro deverá ter claro que a qualidade não é apenas uma meta, um objetivo a ser alcançado, mas sim, um processo contínuo na busca de aperfeiçoamento, tendo como foco, a prestação de serviço que atenda cada vez melhor a clientela que dele se utiliza (SILVA, 1994).

De acordo com Cianciarullo (1997), para assegurar a qualidade da assistência de enfermagem no sistema de saúde contemporâneo são necessários instrumentos aperfeiçoados de mensuração e de avaliação, que reflitam linhas de pensamento tanto qualitativas como quantitativas.

Para avaliação da qualidade dos cuidados de enfermagem, faz-se necessário comparar a assistência prestada com normas e critérios aceitos. A realização de uma medida objetiva dos serviços de enfermagem prestados requer a criação de padrões e critérios de assistência (NONINO, 2006)

Qualidade é um critério diretamente ligado aos padrões assistenciais que se deseja alcançar. Assim, a assistência de enfermagem desenvolvida por meio de inúmeros processos técnico-assistenciais fundamentados em conhecimentos, competências e habilidades específicas, dependerá da existência de recursos humanos em termos qualitativos e quantitativos compatíveis com a sua execução (LAUS, 2003).

Os processos de avaliação da qualidade dos serviços de enfermagem, desenvolvidos de maneira sistemática e contínua, possibilitarão identificar o padrão de qualidade dos cuidados prestados. Assim, ao se analisar a participação da enfermagem na qualificação dos serviços de saúde, pode-se dizer que uma assistência de qualidade prevê avaliações de resultados sistemáticas e possibilita intervenções e ajustes imediatos (NONINO, 2006).

Silva e Pinheiro (2001) afirmam que embora os enfermeiros estabeleçam objetivos, tracem normas e rotinas para a atuação da enfermagem nos serviços de saúde, ainda hoje não se respaldam em sistemas formais de controle de qualidade que contemplem a aplicação de padrões ou critérios mínimos de atendimento, indicadores objetivos de qualidade, processo de sistematização da assistência, o que pode comprometer a prestação de assistência de enfermagem aos clientes. 


\subsection{Avaliação da qualidade da assistência à saúde}

As instituições de saúde têm proposto várias iniciativas nos últimos anos com vistas à avaliação dos serviços, tendo como finalidade atribuir-lhes um grau de certificação segundo a qualidade dos serviços que oferecem.

As formas que os processos de avaliação podem acontecer são variadas, porém a essência está vinculada à necessidade de parar frente a uma situação e pensar, sistematicamente, sobre o que fazer para identificar, compreender, elucidar os obstáculos, as deficiências, os desvios, bem como as facilidades, potencialidades, oportunidades e, assim, propor modificações, ajustes e criar as inovações necessárias que assegurem a melhoria da qualidade (SENTONE, 2005).

Para Zanon (2001), a avaliação está atrelada a estimar, apreciar ou julgar algo, relacionando-o com critérios e valores semelhantes que venham servir de parâmetros.

A introdução de um mecanismo sistemático de avaliação de qualidade de serviços fornecidos pelo profissional aos usuários possibilita a melhoria dos serviços de saúde (VUORI, 1991).

A incorporação da avaliação como prática sistemática nos diversos níveis dos serviços de saúde poderia propiciar aos seus gestores as informações requeridas para a definição de estratégias de intervenção, uma vez que há grande quantidade de informações registradas rotineiramente nos serviços de saúde que não são utilizadas para a análise da situação da saúde, para a definição de prioridades e para a reorientação de práticas (SILVA; FORMIGLI, 1994).

Segundo Menezes (2009), nos últimos anos, especialistas têm trabalhado para desenvolver métodos eficientes que permitam identificar a qualidade da assistência à saúde, possibilitando uma ampliação do uso de metodologias que indiquem os processos e resultados desta assistência.

Novaes (2000) destaca a possibilidade do emprego de três tipologias para a avaliação de serviços: investigação avaliativa, avaliação para a decisão e avaliação para a gestão. Elas diferem quanto ao objetivo, à posição do avaliador, ao enfoque empregado, à metodologia predominante, ao contexto, à forma de utilização da informação produzida, ao juízo formulado e à temporalidade.

Ainda no que tange à avaliação da qualidade dos serviços, Adami (2000) aponta que as atividades disponíveis para assegurar a realização de tal processo 
podem ser divididas em internas e externas. Quanto às internas, destacam-se as Comissões de Avaliação Interna da Qualidade, constituídas por elementos da equipe multidisciplinar, de Auditoria de Enfermagem, de Prevenção e Controle de Infecções Hospitalares, de Ética em Pesquisa, de Gerenciamento de Riscos, de Prevenção Interna de Acidentes e os Serviços de Educação Continuada e de Atendimento ao Cliente. Com relação às externas, a Acreditação Hospitalar, preconizada por órgãos governamentais, é considerada uma prática relevante para a gestão da qualidade e que vem sendo, gradativamente, empregada nas instituições de saúde.

Segundo Teixeira et al (2006) tais instrumentos desempenham papel fundamental na busca pela qualidade dos serviços, porém fomentam a necessidade de elaboração de indicadores de qualidade possíveis de serem empregados e comparados com padrões internos e externos.

A utilização de padrões permite o estabelecimento de indicadores, bem como o acompanhamento e monitorização de sua evolução em um determinado período de tempo ou por um longo período (SENTONE, 2005). A autora destaca que a definição de padrões assistenciais é de fundamental importância para se implementar o controle da qualidade.

Haddad (2004) enfatiza que não é possível existir apenas um conjunto de padrões e recomenda que cada organização e profissão determinem padrões e objetivos que nortearão os profissionais para uma assistência segura e eficaz.

No tocante à avaliação de qualidade no cenário da saúde, o autor de maior destaque tem sido Avedis Donabedian, cujos primeiros trabalhos sobre o tema datam dos anos 60 e cujo modelo é o mais referenciado pelos estudiosos em gestão da qualidade assistencial.

Donabedian (1984) desenvolveu uma discussão sistemática sobre a questão e um de seus artigos expressava dúvidas acerca da natureza do conceito de qualidade, ou seja, apesar de afirmar ser a qualidade uma propriedade do cuidado médico, considerava não estar claro se a mesma era um atributo único, uma classe de atributos funcionalmente relacionados ou um conjunto heterogêneo de fenômenos reunidos pelo uso, razões administrativas ou preferências pessoais. Para o autor, a busca de uma definição para a qualidade deveria se iniciar a partir das dimensões do cuidado médico, a saber: a técnico-científica, a relação interpessoal e as "amenidades" (conforto e estética das instalações e equipamentos). Justificava sua opção pelo estudo da qualidade do cuidado médico, pois mesmo a avaliação de 
programas só se aproximariam, segundo ele, da aferição da qualidade quando o mesmo envolvesse a prestação de cuidado individual.

Posteriormente, Donabedian (1990) passou a considerar a qualidade como um fenômeno complexo, a ser definido a partir dos seguintes atributos do cuidado médico, considerados como os sete pilares da qualidade: eficácia, efetividade, eficiência, otimização, aceitabilidade, legitimidade e equidade. Em 1991, este mesmo autor acrescenta à definição, até então utilizada como um julgamento, tanto sobre o componente técnico quanto sobre as relações interpessoais entre o cliente e o profissional, aquilo que estas características têm de "bom" (goodness). Considerava, ainda, que a qualidade da dimensão técnica do cuidado deveria ser julgada pela sua efetividade, o que corresponde, em última análise, a considerar esses dois termos como equivalentes.

A conceituação de qualidade coloca-se como construção de um modelo normativo para avaliar os serviços de saúde, capaz de monitorar e induzir um balanço cada vez mais favorável entre benefícios e riscos. Quanto à avaliação da qualidade, é fundamental traduzir os conceitos e definições gerais em critérios operacionais, parâmetros e indicadores, validados e calibrados pelos atributos da estrutura, do processo e dos resultados (DONABEDIAN, 1984).

No que se refere à gestão de qualidade, o modelo proposto por Donabedian (1992a) e utilizado amplamente, considera as variáveis estrutura, processo e resultados, podendo ser definida como um arranjo ideal de um vasto conjunto de elementos presentes nesta tríade ou mesmo haver combinações entre elas.

A avaliação da estrutura estuda, fundamentalmente, as características dos recursos de organização administrativa das instituições, recursos físicos e humanos, equipamentos e insumos, perfil dos profissionais empregados, seu preparo e experiência, no que diz respeito a sua adequação às normas e padrões estabelecidos. Essa abordagem aponta para o fato de que boas condições organizacionais de trabalho podem possibilitar um processo adequado de cuidados.

A avaliação do processo descreve as atividades dos serviços prestados; está orientada, principalmente, para análise da competência dos prestadores de serviços. A metodologia dessa abordagem pode ser através da observação direta de prática ou de registros e documentação. O método mais utilizado é o da avaliação retrospectiva do cuidado com base nos registros. 
A avaliação dos resultados corresponde ao resultado do processo, incluindo a satisfação do usuário. Baseia-se no estudo do alcance dos objetivos do cuidado. Destaca-se que a relação entre processo e resultado nem sempre pode ser considerada como uma relação diretamente proporcional; existem diversos fatores que influenciam nessa relação, portanto maus resultados nem sempre indicam processos inadequados.

Fernandes et al (2000) apontam que a qualidade em saúde se dá em torno de três componentes fundamentais: a intervenção técnica, o manejo da relação interpessoal e o ambiente em que se realiza o processo de atenção. Avaliar cada um desses aspectos não é uma tarefa simples, dada a multiplicidade de determinação de cada um deles. Entretanto, constitui-se na possibilidade de poder estimar a qualidade do gerenciamento do cuidado.

Considerando-se, ainda, este referencial, Novaes (2000) afirma que os "guidelines" construídos a partir de estudos clínicos, avaliações tecnológicas e avaliações de programas, resultam de um processo tipicamente "donabediano" e se traduzem em critérios e padrões de qualidade para um determinado serviço. Para sua validação, deve-se utilizar uma pesquisa de avaliação e, em seguida, transformá-los em instrumentos de monitoramento de avaliação para gestão e, assim, podem ser considerados adequados ou não para compor um programa de garantia de qualidade em um serviço.

No que tange, ainda, à avaliação e à aferição dos resultados obtidos na assistência em saúde, propicia uma análise sistemática do conjunto, pois reflete também a qualidade das estruturas e processos integrantes, tornando difícil ignorar a importância de cada um destes elementos no primeiro (MALIK, 2004; DONABEDIAN, 1992a).

Donabedian (1992b) enfatiza ainda que num processo de gestão da qualidade, ao se estabelecer uma avaliação criteriosa, faz-se necessária a seleção de um conjunto de indicadores que representem as três variáveis do processo avaliativo. Isto significa traduzir os conceitos e definições gerais em critérios operacionais, parâmetros e indicadores, validados e calibrados pelos atributos da estrutura, do processo e dos resultados, que possibilitem não somente a estruturação dos serviços, mas que facilitem o acompanhamento, a avaliação e o replanejamento dos processos assistenciais. 
Os indicadores são representações quantitativas ou não de resultados, ocorrências ou eventos de um sistema e constituem-se em um instrumento gerencial de mensuração, sem o qual é impossível a avaliação criteriosa de qualidade ou produtividade. Considerados uma medida objetiva e definida do que se pretende conhecer, permitem, através de seus resultados, evidenciar problemas e propor soluções para que eles não reapareçam (MONTE; ADAMI; BARROS, 2001; BITTAR, 2001).

A função dos indicadores ultrapassa a avaliação da assistência e estes podem ser considerados como insumos necessários para as atividades de planejamento e tomada de decisões e até mesmo para a estruturação de um serviço (KURCGANT; TRONCHIN; MELLEIRO, 2006). Para estas autoras, o indicador geralmente é construído segundo uma expressão matemática, em que o numerador representa o total de eventos predefinidos ou a ser avaliado e o denominador, a população de risco selecionada. Deve-se observar se o parâmetro é confiável, válido, objetivo, sensível e específico. Porém, dificilmente um indicador sozinho poderá ser capaz de retratar a realidade; é mais provável que um grupo deles possa espelhar uma determinada situação.

Assim, indicadores são como sinalizadores voltados para identificar ou dirigir a atenção para assuntos específicos de resultados em uma organização de saúde e, portanto, necessitam ser revistos periodicamente.

Nesta perspectiva, se por um lado, os indicadores tornam-se instrumentos que implicam no conhecimento prévio da clientela, ajustando-os às suas necessidades de saúde, por outro, permitem direcionar os serviços para que esses atinjam níveis de excelência na assistência prestada e aumentem a sua produtividade com a redução de custos. Pautado nessa assertiva, verifica-se que é possível construir instrumentos reguladores da qualidade de assistência de saúde, baseados nos componentes de estrutura, de processo e de resultado considerandose os padrões e critérios de uma dada realidade (TEIXEIRA et al., 2006).

Em decorrência destas proposições, os serviços de saúde têm procurado utilizar diferentes indicadores de resultados que permitam avaliar a estrutura e os processos, a fim de direcionar ações em busca da melhoria contínua dos serviços.

Assim, é possível identificar a necessidade de criação de diferentes estratégias de avaliação das práticas em saúde, identificando o processo de trabalho realizado, bem como as condições em que as práticas assistenciais são executadas, 
confrontando-as com as fundamentações já existentes, frente à importância de aferição dos resultados obtidos no desempenho das instituições.

\subsubsection{Indicadores clínicos de avaliação da assistência à saúde}

$\mathrm{Na}$ avaliação da qualidade da assistência à saúde tem sido cada vez mais frequente a utilização de indicadores clínicos que se constituem em ferramentas essenciais para realização deste processo. Um indicador clínico é definido como uma medida quantitativa contínua ou periódica de variáveis, características ou atributos de um dado processo ou sistema que permite reconhecer resultados desejáveis ou indesejáveis (SÃO PAULO, 2006).

Os indicadores podem ser usados na busca e garantia da qualidade de forma planejada e em conformidade com o atual ambiente de mercado. Eles são importantes para orientar os esforços de melhoria das instituições de saúde, pois possibilitam a avaliação objetiva e quantitativa do desempenho organizacional do ponto de vista clínico (qualidade clínica), bem como do ponto de vista administrativo. Portanto, podem ser utilizados na organização como instrumento de análise, seja do grau de satisfação do cliente ou dos problemas de um procedimento ou serviço. A partir da análise dos indicadores tem-se um caminho a seguir para uma possível tomada de decisão (SOUZA, 2006).

Num processo de avaliação de qualidade em saúde, segundo modelo de Donabedian, as análises da estrutura, do processo ou dos resultados podem ser feitas isoladamente, mas quando realizadas simultaneamente, elas se complementam, possibilitando uma visão do conjunto. A vantagem de um tipo de avaliação sobre outro está na adequação do seu uso, conforme o evento a ser medido. A da estrutura, apesar de determinar padrões mínimos de capacidade de funcionamento de serviços, não assegura alta qualidade da assistência. Estes padrões precisam estar combinados com avaliações de processo. A avaliação de resultado é considerada mais útil para formulação de julgamento do que de melhoria de qualidade e precisa estar estreitamente relacionada com processos de assistência que podem ser modificados. A avaliação de processo é mais sensível para acessar a qualidade do cuidado, mas precisa estar relacionada diretamente com um resultado, ou mesmo, influenciá-lo, e ainda não se encontra bem desenvolvida (SÃO PAULO, 2006). 
Para Menezes (2009), os indicadores não devem ser criados e aplicados indiscriminadamente, mas é necessária a elaboração de critérios para sua construção. Primeiramente, reconhecer previamente a melhor prática disponível a ser avaliada (padrão-ouro), fundamentada em estudos de evidência científica, como revisão sistemática e metanálise e/ou ensaios clínicos controlados. Ou então, na falta destes, poder-se-ia utilizar diretrizes clínicas de recomendações, protocolos, consensos de especialistas, entre outros.

O uso de indicadores clínicos de avaliação pode direcionar o estabelecimento de melhores práticas de saúde, a partir de fundamentação teórico-científica disponível e de consenso de especialistas, orientando o diagnóstico de como as práticas estão ocorrendo e qual a sua conformidade em relação à qualidade esperada.

Nesta perspectiva, recomenda-se a elaboração de critérios que definam as ações passíveis de avaliação de qualidade, tais como identificação da importância do problema considerando sua contribuição na morbi-mortalidade (alto risco), sua associação a altos índices de utilização (alto volume) ou um tratamento de alto custo (alto custo de vida). Além disso, deve-se considerar se a ação pode ser frequentemente monitorada e se existe evidência de variação na sua qualidade. Outro ponto a ser analisado no processo de escolha dos critérios refere-se ao grau de controle dos mecanismos para implementação da prática pelos profissionais, bem como o grau de influência destes sobre o processo de melhoria contínua de qualidade. Pode ser considerado, por exemplo, o controle e qualificação de uma prática regulamentada por legislação como no caso de controle de infecção hospitalar (SÃO PAULO, 2006).

A literatura tem apresentado vários indicadores de resultados da assistência à saúde utilizados para avaliação de processos, tais como ocorrência de eventos adversos relacionados a medicamentos, tempo de internação hospitalar, mortalidade de pacientes cirúrgicos por complicações potencialmente tratáveis, prevalência de úlcera por pressão, queda, PNM e infecções adquiridas no hospital entre outros (WHITMAN et al, 2002; JOINT COMISSION ON ACREDITATION OF HEALTHCARE ORGANIZATION - JCAHO, 2006).

Neste sentido, a IH tem sido uma morbidade bastante fundamentada quanto às ações para seu controle e prevenção, porém o maior desafio tem sido reconhecer as condições em que as práticas assistenciais são realizadas, frente às 
fundamentações já existentes e a dinamicidade de evolução da assistência clínica (SÃO PAULO, 2006).

Sendo a PAVM uma infecção de alta morbi-letalidade é importante utilizar indicadores para medir a qualidade do atendimento prestado pelo serviço de saúde. Por isso há sempre um empenho especial das equipes na sua prevenção (AGÊNCIA NACIONAL DE VIGILÂNCIA SANITÁRIA - ANVISA, 2009a). 
2 Infecção Hospitalar 
As $\mathrm{IH}$ constituem risco significativo à saúde dos usuários dos serviços de saúde, e sua prevenção e controle envolvem medidas de qualificação de assistência hospitalar, de vigilância sanitária e outras, tomadas no âmbito do Estado, do Município e de cada hospital, atinentes ao seu funcionamento (BRASIL, 1998).

Infecção hospitalar é definida em âmbito nacional, conforme Portaria no 2616/98 do Ministério da Saúde (BRASIL, 1998), como aquela adquirida após a admissão do paciente e que se manifeste durante a internação ou após a alta, quando puder ser relacionada com a internação ou procedimentos hospitalares.

A problemática da IH no Brasil cresce a cada dia, considerando que o custo do tratamento dos clientes com IH é três vezes maior que o custo dos clientes sem infecção. Os índices de IH permanecem altos, 15,5\%, mesmo com a legislação vigente no país, correspondendo a 1,18 episódios de infecção por cliente internado com IH nos hospitais brasileiros. Um agravante é o fato de as instituições públicas de saúde possuírem a maior taxa de prevalência de IH no país, 18,4\% (MOURA et al, 2007).

Entretanto, é importante ressaltar que as $\mathrm{IH}$ não são causadas por microorganismos necessariamente adquiridos no ambiente hospitalar; grande parte delas é causada pela própria microbiota do individuo e que são inoculados no meio interno através dos procedimentos invasivos. Por este motivo, a etiologia dos processos infecciosos é influenciada pela sua topografia, considerando-se a microbiota habitual de cada sítio corporal (GASPAR; RODRIGUES, 2009).

No Brasil, de 5 a $15 \%$ dos pacientes hospitalizados e de 25 a $35 \%$ dos pacientes admitidos em UTI adquirem IH, sendo a quarta causa de mortalidade. Apesar de o número de leitos de UTI representar, geralmente, cerca de 5 a 10\% dos leitos de um hospital, estima-se que nesse setor ocorram aproximadamente $25 \%$ de todas as $\mathrm{IH}$. Os índices de $\mathrm{IH}$ nas UTI tendem a ser maiores do que aqueles encontrados nos demais setores do hospital, devido à gravidade das patologias de base, aos procedimentos invasivos utilizados ao longo do tempo de internação e ao comprometimento imunológico, que tornam os pacientes mais susceptíveis à aquisição de infecções. A PNM hospitalar ocasionada por bactérias multirresistentes em pacientes sob VM, infecções do trato urinário, infecções de sítio cirúrgico e de tecidos moles têm sido as mais frequentemente diagnosticadas nos pacientes internados em UTI (GUIMARÃES; ROCCO, 2006). 
Para David (1998) a infecção é manifestação frequente no paciente grave internado em UTI e os métodos invasivos como a cateterização urinária, a intubação traqueal, a VM e cateteres intravasculares são responsáveis por grande número de infecções.

Gaspar e Rodrigues (2009) salientam que o desenvolvimento de infecção relacionada a um procedimento invasivo será tanto menos provável quanto maior for o rigor técnico observado na sua instalação e manutenção, e ainda quanto menor for a duração da sua utilização.

Depreende-se, portanto, que os inúmeros avanços tecnológicos relacionados aos procedimentos invasivos para diagnóstico e tratamento, apesar dos indiscutíveis benefícios, contribuíram para o aparecimento de micro-organismos multirresistentes e tornaram as IH um problema relevante para as instituições de saúde.

\subsection{Pneumonia adquirida em hospital}

Os dados epidemiológicos sobre PNM relacionada à assistência à saúde são imprecisos porque há falta de critérios de diagnóstico uniformes e claros. A maioria destas infecções é associada à VM e há mais dados epidemiológicos sobre este tipo de PNM adquirida no ambiente hospitalar (ANVISA, 2009a).

A cada ano ocorrem nos Estados Unidos entre 5 e 10 episódios de PNM relacionados à assistência à saúde por 1000 admissões. Estas infecções são responsáveis por $15 \%$ das infecções relacionadas à assistência à saúde e aproximadamente $25 \%$ de todas as infecções adquiridas nas UTI (ANVISA, 2009a).

A pneumonia adquirida no hospital (PAH) é aquela que ocorre após 48 horas da admissão hospitalar, geralmente tratada na unidade de internação (enfermaria/apartamento), não se relacionando à intubação endotraqueal e VM; podendo, entretanto, ser encaminhada para tratamento em UTI, quando se apresenta ou evolui de forma grave. Dentro deste conceito, deve ser considerado o tempo médio de incubação característico de cada micro-organismo. Devido a implicações etiológicas, terapêuticas e prognósticas, a PAH tem sido classificada quanto ao tempo decorrido desde a admissão até o seu aparecimento. A PAH precoce é a que ocorre até o quarto dia de internação, sendo considerada tardia a que se inicia após cinco dias da hospitalização (AMERICAN THORACIC SOCIETY, 2005). 
No Brasil, considera-se PAH aquela diagnosticada após 72 horas de internação do paciente (FERNANDES; FERNANDES; RIBEIRO FILHO, 2000).

A magnitude do problema está no fato de a PNM permanecer como uma das principais causas de morte em todo o mundo. Nos Estados Unidos da América (EUA) ela está entre as cinco mais frequentes em pessoas acima de 65 anos e é a principal causa de morte nos países em desenvolvimento (FERNANDES; FERNANDES; RIBEIRO FILHO, 2000).

A PAH, especialmente quando associada à VM, representa um grande desafio diagnóstico e terapêutico, a despeito de todo o progresso da medicina atual. A maior longevidade da população, a utilização de fármacos imunossupressores, e o desenvolvimento de novos procedimentos médicos intervencionistas, modificaram a interação hospedeiro-agente infeccioso, favorecendo a emergência de novos microorganismos e o desenvolvimento de patógenos resistentes (AMERICAN THORACIC SOCIETY, 2005; SOCIEDADE BRASILEIRA DE PNEUMOLOGIA E TISIOLOGIA SBPT, 2007).

A PAVM é aquela que surge 48-72 horas após intubação endotraqueal e instituição da VM invasiva. De modo similar, a PAVM também é classificada em precoce e tardia. A PAVM precoce é a que ocorre até o quarto dia de intubação e início da VM, sendo a PAVM tardia a que se inicia após o quinto dia da intubação e VM (AMERICAN THORACIC SOCIETY, 2005).

Estudos apontam a PNM como a segunda principal infecção nosocomial e quando associada à VM é a infecção que mais acomete os pacientes internados em UTI, sendo que sua incidência pode variar de 9 a $68 \%$, dependendo do método diagnóstico usado e da população estudada. Sua alta letalidade varia entre 33 e $71 \%$ e a relação entre caso e fatalidade pode atingir até $55 \%$. Oitenta e seis por cento dos casos de pneumonia hospitalar estão associados com a VM. Por outro lado, 9 a 27\% dos pacientes ventilados desenvolvem PNM. A prevalência relatada é de 20,5 a 34,4 casos de PNM por 1.000 dias de VM e de 3,2 casos por 1.000 dias em pacientes não ventilados. Há uma variação entre $10 \%$ e $50 \%$ dos pacientes intubados que podem desenvolver PNM, com risco aproximado de 1 a $3 \%$ por dia de intubação endotraqueal e VM (CRAVEN; STEGER, 1995; GEORGE et al, 1998; LODE et al, 2000; TEIXEIRA et al, 2004; GUIMARÃES; ROCCO, 2006).

Vários estudos demonstram que a incidência desta infecção aumenta com a duração da VM e apontam taxas de ataque de aproximadamente $3 \%$ por dia durante 
os primeiros cinco dias de ventilação e depois $2 \%$ para cada dia subsequente (ANVISA, 2009a).

Segundo Teixeira et al (2004), a incidência da PAVM é alta, podendo variar entre 6 e 52\%, dependendo da população estudada, do tipo de UTI, e do tipo de critério diagnóstico utilizado, pois, apesar de ser uma infecção extremamente importante, é um dos diagnósticos mais difíceis de ser firmado num paciente gravemente doente. Quando comparada a outras infecções nosocomiais, tais como as do trato urinário e as da pele, em que a mortalidade varia de 1 a 4\%, a PAVM é um importante preditor de mortalidade, variando entre 24 e $50 \%$, podendo atingir mais de $70 \%$ quando causada por micro-organismo multirresistente.

A mortalidade global nos episódios de PAVM, de acordo com a ANVISA (2009a), varia de 20 a 60\%, refletindo em grande parte a severidade da doença de base dos pacientes, a falência de órgãos e especificidades da população estudada e do agente etiológico envolvido. Estimativas da mortalidade atribuídas a esta infecção variam nos diferentes estudos, mas aproximadamente $33 \%$ dos pacientes com PAVM morrem em decorrência direta desta infecção. Além da mortalidade, o impacto desta infecção, especialmente da PAVM, traduz-se no prolongamento da hospitalização, em torno de 12 dias e no aumento de custos, em torno de 40000 dólares por episódio.

Dados do Estado de São Paulo em 2008 mostraram que a mediana da incidência de PAVM foi de 16,25 casos por 1.000 dias de uso de ventilador em UTI de adultos, mas alcançou até 21,06 casos por 1.000 dias de uso de ventilador em UTI coronarianas (ANVISA, 2009a).

Em 2008, a incidência de PAVM nas UTI clínico-cirúrgicas de hospitais de ensino nos EUA foi de 2,3 casos por 1.000 dias de uso de ventilador e de 1,2 casos por 1.000 dias de uso de ventilador em UTI coronarianas (ANVISA, 2009a). Estes números sugerem que a incidência nacional pode ser mais elevada do que a desejada. Infelizmente, não há dados nacionais atualizados por falta de uma coleta sistemática e padronizada em todos os Estados.

Estudo realizado no Brasil intitulado de Magnitude das Infecções Hospitalares e Avaliação da Qualidade das Ações de Controle de Infecção Hospitalar constatou que os maiores índices de pacientes com infecção foram obtidos nos hospitais públicos $(18,4 \%)$, as maiores taxas de infecção obtidas concentravam-se nas unidades de terapia intensiva e queimados, sendo a PNM a principal infecção. Esta 
infecção ocupou o primeiro lugar nas UTI adulto e pediátrica e a VM aumentou em dez vezes o risco para o paciente desenvolver PNM (PRADE et al, 1995).

A patogênese da PNM relacionada à assistência à saúde envolve a interação entre patógeno, hospedeiro e variáveis epidemiológicas que facilitam esta dinâmica. Vários mecanismos contribuem para a ocorrência destas infecções, porém o papel de cada um destes fatores permanece controverso, podendo variar de acordo com a população envolvida e o agente etiológico (ANVISA, 2009a).

Para o desenvolvimento de $\mathrm{PAH}$, há a necessidade de que os patógenos alcancem o trato respiratório inferior e sejam capazes de vencer os mecanismos de defesa do sistema respiratório, que incluem os mecânicos (reflexo glótico e da tosse, e sistema de transporte mucociliar), humorais (anticorpos e complemento), e celulares (leucócitos polimorfonucleares, macrófagos e linfócitos) (AMERICAN THORACIC SOCIETY, 2005).

São considerados fontes de patógenos para $\mathrm{PAH}$ muitos dispositivos e equipamentos utilizados no ambiente hospitalar, e seus elementos associados, como: ar, água, sondas, tubos e fômites (SBPT, 2007).

Outra fonte de infecção decorre da transferência de patógenos entre pacientes, ou entre estes e os profissionais de saúde denominado transmissão cruzada. Além disso, uma série de fatores do hospedeiro, ou de intervenções terapêuticas a ele aplicadas, favorece a colonização por micro-organismos hospitalares, como: rebaixamento do nível de consciência, imunossupressão, extremos de idade, gravidade da doença de base, cirurgias prévias (torácicas ou abdominais altas), depressão do sensório, doença cardiopulmonar, necessidade de terapia respiratória, desde nebulizações e oxigenoterapia até a utilização de prótese traqueal e suporte ventilatório invasivo, além de procedimentos que envolvem manipulação do trato respiratório (AMERICAN THORACIC SOCIETY, 2005; SÃO PAULO, 2006).

Ainda segundo o Guideline da Amerian Thoracic Society (2005), a via principal de entrada de micro-organismos no trato respiratório inferior consiste na aspiração de secreção da orofaringe. Nos casos de pacientes intubados, podem originar-se da secreção que se acumula acima do balonete do tubo. Outros reservatórios potenciais são as cavidades sinusais e o trato digestivo superior, embora ainda persistam controvérsias a esse respeito. A presença de um biofilme, com contaminação por bactérias dentro do tubo traqueal, também tem sido 
implicada como uma fonte para inoculação de micro-organismos nos pulmões, durante a aspiração traqueal ou realização de broncoscopia. A inalação de aerossóis contaminados constitui via de acesso de patógenos aos pulmões. O acesso pela corrente sanguínea, seja a partir de cateteres ou por translocação bacteriana a partir do trato gastrointestinal, também deve ser considerado.

As Diretrizes Brasileiras para Tratamento das Pneumonias Adquiridas no Hospital e das Associadas à Ventilação Mecânica, em 2007, revelaram que o desenvolvimento de PAVM é primariamente devido à aspiração de secreções de orofaringe, do condensado formado no circuito do respirador, ou do conteúdo gástrico colonizado por bactérias patogênicas. Deste modo, orientam o manejo cuidadoso do tubo, sua fixação e posicionamento adequados, devem ser verificados diariamente, e a pressão do balonete deve ser mantida em níveis não inferiores a $20 \mathrm{~cm} \mathrm{H} 2 \mathrm{O}$ (15 mmHg), para prevenir excesso de aspiração, e não superiores a $30 \mathrm{~cm} \mathrm{H} 2 \mathrm{O}(23 \mathrm{mmHg}$ ) para evitar isquemia da mucosa traqueal. O circuito do ventilador pode ser uma fonte de patógenos, e já há evidência de que a formação de condensado com acúmulo de líquido contaminado por patógenos do próprio paciente, se torna fonte de infecção para o mesmo. Deve-se evitar desvio inadvertido de líquidos do circuito para o tubo, ou de volta para o umidificador, especialmente durante manobras realizadas para modificar o decúbito do paciente, e ao se elevar a grade lateral do leito, quando se utiliza nebulização. Todos os dispositivos que favoreçam os episódios aspirativos (sondas digestivas e cânulas traqueais) devem ser removidos o mais precocemente possível, ou seja, assim que as condições clínicas do paciente o permitirem (SBPT, 2007).

O principal fator de risco para $\mathrm{PAH}$ é a intubação e a VM, que quando presente aumenta o risco de 3 a 21 vezes. A incidência de PAVM aumenta em 3\% por dia na primeira semana de ventilação, $2 \%$ por dia na segunda semana e $1 \%$ por dia na terceira semana, com aproximadamente $50 \%$ dos episódios ocorrendo nos quatro primeiros dias de VM. Outros fatores predisponentes importantes em pacientes sob ventilação relacionam-se à gravidade da doença, doença pulmonar obstrutiva crônica (DPOC), idade e uso prévio de antibióticos (MEDEIROS, 1992; SBPT, 2007).

Os fatores de risco para PAH podem ser classificados em modificáveis ou não modificáveis. Os fatores de risco não modificáveis são: idade, escore de gravidade, presença de DPOC, doenças neurológicas, traumas e cirurgias. A interferência nos 
fatores modificáveis pode ser realizada por meio de medidas de relativa simplicidade, tais como: higienização das mãos; instituição de protocolos para prescrições de antimicrobianos; e vigilância microbiológica, com informação periódica aos profissionais, quanto à prevalência e resistência microbiana (SBPT, 2007).

Enfatiza-se, então, a necessidade de medidas preventivas para PNM, tais como diminuição da colonização da orofaringe, da traquéia e do estômago, redução da possibilidade de aspiração de secreções respiratórias ou conteúdo gástrico, cuidados com a VM e intubação traqueal, cuidados com a transmissão cruzada de infecção através das mãos e de materiais ou equipamentos, cuidados com pacientes que sofram cirurgias abdominais, entre outras (SÃO PAULO, 2006).

Outras iniciativas, tais como: implementação de protocolos de sedação e desmame ventilatório, bem como a remoção precoce de dispositivos invasivos, podem reduzir a prevalência de infecções nosocomiais (SBPT, 2007).

Sabe-se que a patogênese da PNM é multifatorial e, conforme Fernandes, Fernandes e Ribeiro Filho (2000), não se deve esperar "resultados mágicos de nenhuma medida de controle tomada isoladamente". Segundo estes autores, o sucesso de medidas preventivas específicas implantadas em uma unidade hospitalar depende do envolvimento de toda equipe profissional, sendo fundamental a educação permanente de todos eles.

Identifica-se, portanto, que os profissionais de saúde envolvidos na assistência direta podem contribuir para o aumento do risco das $\mathrm{IH}$ quando não adotam ou não aderem corretamente às medidas de controle e prevenção. Para Menezes (2009), eles contribuem para a disseminação de micro-organismos entre pacientes pela ausência ou redução da higienização das mãos, reprocessamento e manuseio inadequado dos materiais médico-hospitalares, dentre outros.

Há um consenso de que as UTI são consideradas unidades cruciais no panorama das $\mathrm{IH}$, pois convivem com um uso rotineiro de técnicas invasivas, uma alta densidade de pacientes e suscetibilidade dessa população, geralmente portadora de doenças graves, o que propicia o aumento do risco de infecção por micro-organismos multirresistentes.

Devido a sua relevância clínica e seu perfil epidemiológico, a PAVM precisa ser estudada distintamente dentro das PNM nosocomiais, representando um dos principais desafios enfrentados pelos profissionais de saúde em sua prática diária, 
particularmente nas UTI, requerendo o máximo de conhecimentos e todas as possibilidades terapêuticas disponíveis. Neste sentido, a identificação das ações que a equipe de saúde realiza habitualmente em UTI para prevenção de PAVM é imprescindível, apontando, assim, a qualidade destes cuidados e seu impacto sobre a incidência de PNM nosocomial.

Neste contexto, além de expor a magnitude do problema, identifica-se a necessidade de serem exploradas novas estratégias de enfrentamento, frente às dificuldades que o tratamento da PAVM requer, por ser um processo dinâmico e complexo.

Realizar vigilância de PAVM com definições padronizadas em UTI, calcular taxas de PAVM, dar um retorno destes índices para a equipe de saúde e, sobretudo, associar estas taxas com as medidas de prevenção pertinentes, são medidas fortemente recomendadas. Este indicador pode tornar-se um importante aliado na avaliação da qualidade da assistência (ANVISA, 2009a).

Neste caminho, em consonância com as diretrizes de criação de novas estratégias de avaliação, que permitam o reconhecimento das condições em que as práticas de controle de $\mathrm{IH}$ são realizadas, de modo a assegurar a aplicação das medidas baseadas em evidências científicas, em 2003 foi desenvolvido um projeto de políticas públicas, para a construção de indicadores clínicos de avaliação da qualidade de práticas de controle de IH. O projeto intitulado de Manual de Avaliação da Qualidade de Práticas de Controle de Infecção Hospitalar foi concluído em 2006 e apresenta 59 indicadores distribuídos em cinco grupos temáticos: a) Programas de Controle de $\mathrm{IH}$; b) Antimicrobianos; c) Procedimentos Assistenciais; d) Processamento de Artigos Odonto-Médico-Hospitalares e e) Riscos Ocupacionais Biológicos (SÃO PAULO, 2006).

No que se refere ao grupo dos Procedimentos Assistenciais, este foi desmembrado nas seguintes práticas: Controle e Prevenção de Infecção da Corrente Sanguínea Associada a Cateter Vascular Central de Curta Permanência (CS); Controle e Prevenção de Infecção do Sítio Cirúrgico (SC); Controle e Prevenção de Infecção Respiratória (IR); Controle e Prevenção de Infecção do Trato Urinário Associada a Cateter Vesical (IU); Indicação e Aplicação de Normas de Isolamento e Precauções (IS) e Higiene das Mãos (HM).

A avaliação proposta teve o objetivo de criar indicadores clínicos que permitam à instituição ou à unidade, uma análise contínua da qualidade dos 
procedimentos executados. Sua construção baseou-se no modelo conceitual de Donabedian, contemplando estrutura, processo e resultado (SÃO PAULO, 2006).

Uma prática relevante no controle de $\mathrm{IH}$, conforme apresentado, reside na prevenção da PAH, particularmente quando associada à VM. Nesta direção, identifica-se a importância da execução adequada das recomendações já existentes para a redução e prevenção dessa infecção, ou seja, a adoção das melhores práticas assistenciais.

Diante do exposto, este estudo pretende avaliar a conformidade das práticas de controle e prevenção de PAVM em uma UTI adulto, utilizando um indicador proposto no Manual de Avaliação da Qualidade de Práticas de Controle de Infecção Hospitalar. 
3 Objetivos 


\subsection{Objetivo geral}

Avaliar a qualidade da assistência à saúde prestada em uma Unidade de Terapia Intensiva, quanto ao uso das medidas de prevenção e controle de pneumonia em pacientes com rebaixamento do nível de consciência e/ou nutrição por sondas submetidos à ventilação mecânica.

\subsection{Objetivos específicos}

Calcular o índice de conformidade das medidas de prevenção e controle de pneumonia associada à ventilação mecânica por meio da utilização de um indicador clínico.

Identificar o valor do índice de gravidade (APACHE II), o risco de óbito e o desfecho de cada paciente participante do estudo.

Caracterizar o índice de conformidade para as medidas de prevenção e controle de pneumonia associada à ventilação mecânica segundo o turno de trabalho e variáveis obervadas. 
4 Metodologia 


\subsection{Tipo de pesquisa}

Trata-se de um estudo descritivo exploratório, com abordagem quantitativa.

Para Polit, Beck e Hungler (2004) na pesquisa quantitativa há uma coleta sistemática de informações numéricas, resultante de mensuração formal que ocorre em condições controladas e utiliza-se de procedimentos estatísticos para análise.

Quanto à tipologia da investigação optou-se pela avaliação com enfoque no processo, já que este é o elemento central do modelo donabediano (DONABEDIAN, 1992a).

Um estudo de avaliação pode ser classificado em três modalidades: processo ou implementação, resultado ou desfecho e impacto. No caso da presente pesquisa, ela se insere na avaliação de processo, realizada quando há necessidade de informações descritivas sobre o processo pelo qual um programa ou procedimento foi implementado e como eles funcionam na atualidade. Este tipo de avaliação também pode ser referida como formativa e envolve um exame em profundidade da operacionalização de um programa, com coleta de dados tanto qualitativos como quantitativos (POLIT; BECK; HUNGLER, 2004).

A avaliação processual encoraja os profissionais a concentrar-se naquilo que realmente possa contribuir diretamente para melhorar os resultados de saúde, sendo a mais sensível para acessar qualidade do cuidado. Para ser válida, precisa estar estreitamente relacionada com um resultado, ou mesmo influenciá-lo (SÃO PAULO, 2006).

\subsection{Local e recursos humanos}

O estudo foi realizado em duas unidades de UTI adulto de um hospital público de ensino de grande porte e nível terciário, na cidade de Ribeirão Preto - SP, vinculado à Faculdade de Medicina de Ribeirão Preto - Universidade de São Paulo (USP) que atende pacientes em urgência e emergência, de alta complexidade e conta com 692 leitos na Unidade Campus e 211 leitos na Unidade de Emergência, local deste estudo. A clientela atendida é, exclusivamente, vinculada ao SUS e serve de referência para a região da Divisão Regional de Saúde XIII (DRS XIII).

O referido hospital serve como campo de estágio para vários cursos de graduação em saúde, como medicina, enfermagem, nutrição, fisioterapia, fonoaudiologia e física médica da USP, além de contar com programas de 
aprimoramento profissional, residência médica e pós-graduação senso estrito em diversas áreas da atenção à saúde.

As unidades em estudo possuem 17 leitos distribuídos em dois andares, com 10 e 7 leitos, respectivamente, destinados ao atendimento de pacientes adultos em estado crítico ou potencialmente crítico, de ambos os sexos e portadores de patologias diversas. A unidade apresenta taxa de ocupação de 93,2\%, com média de 15,8 pacientes/dia e média de permanência igual 9,1dias, dados fornecidos pelo Serviço de Arquivo Médico (SAME) do referido hospital (USP, 2009) ${ }^{2}$.

Os profissionais que compõem a equipe de saúde da UTI adulto são assim distribuídos: dois médicos assistentes para cada um dos três turnos de trabalho (manhã, tarde e noite), com carga horária de 24 horas semanais; três médicos residentes nos turnos manhã e tarde e um no turno da noite; 18 enfermeiros; 50 auxiliares/técnicos de enfermagem que estão presentes na unidade 24 horas por dia, todos os dias da semana por meio da divisão em turnos, e cumprem carga horária de 30 ou 36 horas semanais; 4 fisioterapeutas, sendo dois para período da manhã todos os dias da semana e dois no período da tarde de segunda a sexta-feira; 1 assistente social e 1 psicóloga que atendem pacientes e familiares, conforme demanda do setor, de segunda a sexta-feira, com carga horária de 30 horas semanais.

\subsection{População e amostra}

Os sujeitos da pesquisa foram os pacientes internados no período de coleta de dados que obedeceram ao critério de inclusão: internação na UTI sob assistência ventilatória invasiva com rebaixamento de consciência e/ou nutrição por sondas digestivas.

Para fins de inclusão no estudo, foram considerados consciência e rebaixamento do nível de consciência as definições apresentadas a seguir:

> Consciência: pode ser descrita como a situação em que o indivíduo tem total consciência de si próprio e do meio externo, é conhecedor das relações de tempo, espaço, fatos e pessoas ao se redor (IANKOVA, 2006).

$>$ Nível de consciência: estado de alerta comportamental, condição em que o indivíduo está desperto e em contato com o ambiente externo (STAVALE, 1996).

${ }^{2}$ UNIVERSIDADE DE SÃO PAULO. Faculdade de Medicina de Ribeirão Preto. Hospital das Clínicas. Avaliação hospitalar das especialidades Ref: 01/07/2008 a 31/05/2009: relatório. Ribeirão Preto: USP/FMRP/HC, 2009. 
O conteúdo de consciência envolve a cognição, o acesso que temos aos dados armazenados em córtex que nos torna capaz de compreender fatos e responder de forma condizente às diversas situações (POSNER et al, 2007). O nível de consciência pode ser avaliado pela Escala de Coma de Glasgow, utilizando como parâmetros as respostas motoras, verbais e oculares, sendo que a pontuação pode variar de no mínimo 3 a no máximo 15 pontos: pontuação entre 3-7 significa um coma grave, de 8-12 coma moderado e de 13-15 um estado de consciência normal (BUSHNIK et al, 2003).

No período estabelecido para coleta dos dados foram internados 114 pacientes, porém apenas 38 foram elegíveis para este estudo.

\subsection{Instrumentos e procedimentos de coleta de dados}

\subsubsection{Instrumentos}

Para coleta dos dados foram utilizados dois instrumentos, sendo que o primeiro (APÊNDICE A) contém dados demográficos e clínicos como procedência e destino, tempo de internação prévia e na UTI. Para alcance dos objetivos, ainda foram coletados dados referentes ao desenvolvimento de pneumonia durante a internação na UTI e à gravidade dos pacientes que pode ser identificada por meio de utilização de instrumentos de avaliação conhecidos mundialmente, como o Acute Physiology and Chronic Health Evalution II (APACHE II), calculando-se valor e risco de óbito. Os índices de gravidade têm como objetivo principal a descrição quantitativa do grau de disfunção orgânica de pacientes gravemente enfermos, cuja gravidade é traduzida em valor numérico a partir das alterações clínicas e laboratoriais existentes ou do tipo/número de procedimentos utilizados, permitindo a avaliação de desempenho da UTI e da eficiência do tratamento realizado (ANDREI et al, 2006). Conforme Fernandes, Fernandes e Ribeiro Filho (2000), um índice acima de 20 está associado com um aumento de duas vezes no risco de infecção hospitalar.

O segundo instrumento (APÊNDICE B) utilizado, na forma de indicador clínico processual, foi desenvolvido e validado quanto ao seu conteúdo por um grupo de especialistas e disponibilizado no Manual de Indicadores de Avaliação de Práticas de Controle de Infecção Hospitalar (SÃO PAULO, 2006). 
Este instrumento cujo título é Indicador de Avaliação da Adesão às Medidas de Prevenção e Controle de Pneumonia em Pacientes de Alto Risco (IRPR) é de domínio público e monitora a aplicação de algumas medidas de controle e prevenção de pneumonia hospitalar, a saber: decúbito elevado (entre 30 e 45ํ), fisioterapia respiratória, utilização de soluções estéreis nos equipamentos de terapia respiratória e adesão à rotina de troca dos inaladores estabelecida na instituição. Segundo recomendação, também é possível incorporar outras medidas a critério do grupo avaliador.

Este indicador contém uma planilha para registro das avaliações e um construto operacional, que descreve e orienta a aplicação da avaliação da prática a ele correspondente. Está disposto em uma operação concreta e indica o que se avalia e como deve ocorrer a coleta de informações e sua mensuração, visando garantir uniformidade na avaliação e legitimidade na representação empírica dos dados, além de apresentar a melhor prática disponível, fundamentada cientificamente, permitindo calcular índices de conformidade após avaliação (MENEZES, 2009).

Para fins de realização da presente investigação e para atender os objetivos propostos, foram introduzidas modificações no instrumento original (ANEXO B), acrescendo-se dados relativos à caracterização dos sujeitos da pesquisa. Optou-se por elaborar planilha individual por pacientes contendo, além dos dados originais, itens como presença de ventilação mecânica, rebaixamento do nível de consciência, sonda nasogástrica/sonda nasoentérica (SNG/SNE) e subdividiu-se a planilha de avaliação diária com o objetivo de registrar as observações coletadas nos períodos manhã, tarde e noite.

Segundo a literatura, as medidas para avaliação originalmente propostas no documento, constituem as de melhor evidência nas recomendações de diretrizes clínicas (SÃO PAULO, 2006).

Deste modo, foram incluídas as seguintes categorias de evidência:

$>$ soluções estéreis $(A)$;

$>$ inalador e/ou umidificador respeitando a rotina de troca estabelecida (C);

$>$ atendimento diário de fisioterapia respiratória $(\mathrm{C})$;

$>$ cabeceira elevada a 30-45은

Durante a elaboração deste indicador os autores basearam-se em vários estudos científicos e diretrizes clínicas nacionais e internacionais que utilizam várias formas de categorização de evidências de recomendações (como IA, IIA, IB, IIB, IC 
do Guidelines do CDC; 3, 2, 1 do Guidelines britânicos; I, II, III da SHEA - American Society for Epidemiology in Health e la, Ib, Ila, Ilb, III, IV e O da Agência de Saúde e Pesquisa dos EUA), sendo necessária a elaboração de uma classificação própria, que englobasse as diferentes categorias apresentadas nestas publicações. Portanto, de acordo com sua "força" ou grau de evidência, a fundamentação dos indicadores foi classificada em $A, B$, e $C$, sendo:

A: estudos isolados de evidência científica com revisão sistemática e metanálise; um ou mais estudos científicos de investigação do tipo experimental controlada e randomizada, com grupos controle e experimental; recomendações de entidades identificadas como a melhor categoria (exemplo: IA-Guidelines CDC; 3Guidelines britânico; etc);

B: um ou mais estudos científicos controlados dos tipos prospectivos observacionais e sequenciais; estudos quase experimentais, dos tipos prospectivos comparando grupos no quais a locação não foi randomizada; revisões sistemáticas de literatura, sem metanálise, com análise da qualidade metodológica dos estudos considerados; recomendações de entidades identificadas como a segunda melhor categoria (exemplo: IB-Guidelines CDC; 3-Guidelines britânico; etc);

C: estudos observacionais não experimentais, como pacientes recebendo tratamento comparado com estudos de controles de história, de caso-controle, de correlação; recomendações de entidades identificadas como a terceira e demais categorias; documentos de grupos de consenso de especialistas; revisão de literatura, sem análise de qualidade metodológica dos estudos considerados; normas governamentais; recomendações não categorizadas, presentes em livros e artigos que descrevem etapas do procedimento sob forte justificação teórico-prática.

Para identificação do índice de conformidade às medidas de prevenção e controle de PAVM em pacientes de alto risco foi utilizada a equação descrita abaixo, extraída do Manual supra citado:

$>\mathrm{O}$ numerador consistiu do total de pacientes sob assistência ventilatória e com rebaixamento de consciência e/ou nutrição por sondas digestivas em que as medidas para a prevenção de pneumonia hospitalar (decúbito elevado igual ou maior que $30^{\circ}$, fisioterapia respiratória diária, utilização de soluções estéreis nos equipamentos de terapia respiratória e adesão à rotina de troca dos circuitos de terapia inalatória estabelecida na instituição) são corretamente aplicadas. 
$>\mathrm{O}$ denominador foi $\mathrm{o}$ total de pacientes sob assistência ventilatória com rebaixamento de consciência e/ou nutrição por sondas digestivas em que as medidas de controle para pneumonia hospitalar, descritas no numerador, forem avaliadas.

O valor ideal do indicador é $100 \%$ de conformidade. Desta forma, quanto maior o valor obtido no cálculo maior a qualidade da assistência na prevenção da pneumonia associada à ventilação mecânica.

A forma de construção da planilha do indicador possibilita realizar também avaliação individual da conformidade a cada componente de controle da pneumonia hospitalar (SÃO PAULO, 2006).

Buscando rigor cientifico, há a necessidade de estabelecer padrões para a busca das informações e critérios para avaliação dos dados observados. Seguiu-se, então, a orientação do Manual de Indicadores de Avaliação de Práticas de Controle de Infecção Hospitalar (SÃO PAULO, 2006), descritas no quadro abaixo.

\section{Quadro 1 - Fontes de informação e critérios para avaliação das medidas específicas de prevenção e controle de PAVM (IRRP)}

\begin{tabular}{|c|c|c|}
\hline Critérios & Fontes de informação & Critérios para avaliação \\
\hline $\begin{array}{c}\text { Uso de soluções estéreis } \\
\text { para nebulizadores e } \\
\text { umidificadores }\end{array}$ & Observação direta & $\begin{array}{c}\text { Considerar Atende (A) quando não } \\
\text { forem encontrados frascos de água } \\
\text { destilada abertos ou seringas com } \\
\text { soro fisiológico preparadas }\end{array}$ \\
\hline $\begin{array}{c}\text { Circuito de terapia inalatória } \\
\text { (inalador e/ou umidificador) } \\
\text { em uso e respeitando a } \\
\text { rotina de troca estabelecida }\end{array}$ & $\begin{array}{c}\text { Verificar se existe rotina } \\
\text { descrita para cuidado com } \\
\text { estes materiais e checar se a } \\
\text { mesma está sendo seguida }\end{array}$ & $\begin{array}{c}\text { Considerar A quando a rotina } \\
\text { estabelecida na instituição está } \\
\text { sendo seguida pelas equipes das } \\
\text { unidades }\end{array}$ \\
\hline $\begin{array}{c}\text { Atendimento diário de } \\
\text { fisioterapia respiratória }\end{array}$ & $\begin{array}{c}\text { Prontuário do paciente, } \\
\text { procurar as informações na } \\
\text { evolução e anotações da } \\
\text { equipe de fisioterapia }\end{array}$ & $\begin{array}{c}\text { Considerar A para a presença de } \\
\text { anotação diária de fisioterapia; } \\
\text { registrar Sem Aplicação (SA) nos } \\
\text { casos em que o paciente tenha } \\
\text { contraindicação da assistência da } \\
\text { fisioterapia }\end{array}$ \\
\hline $\begin{array}{c}\text { Cabeceira elevada a 30-45o } \\
\text { (VM ou coma ou sedação) }\end{array}$ & Observação direta & $\begin{array}{c}\text { Considerar A para observação } \\
\text { positiva; considerar SA nos casos } \\
\text { em que o paciente tenha contra- } \\
\text { indicação deste posicionamento }\end{array}$ \\
\hline
\end{tabular}

Fonte: Manual de Indicadores de Avaliação de Práticas de Controle de Infecção Hospitalar (SÃO PAULO, 2006). 
Conforme orientação do referido manual, o mesmo paciente pode ser avaliado em dias consecutivos durante o período de auditoria, pois a situação encontrada pode ser diferente; a presença da situação Não Atende (NA) para qualquer componente sob avaliação deve ser avaliada como não conforme na conclusão deste paciente. Ressalta-se, ainda, que as avaliações são consideradas SA em pacientes que, mesmo sob os critérios de inclusão, apresentam alguma contraindicação para manutenção de cabeceira elevada ou para procedimentos de fisioterapia, devendo a informação estar registrada no prontuário; desconsiderar a avaliação caso haja duas unidades de avaliação classificadas como SA (SÃO PAULO, 2006).

\subsubsection{Procedimento de coleta dos dados}

Este processo compreendeu a realização de duas etapas. Na Etapa 1 os dados foram coletados conforme orientação do construto operacional do indicador, disponibilizado no Manual de Indicadores de Avaliação de Práticas de Controle de Infecção Hospitalar (SÃO PAULO, 2006), utilizando a observação direta e revisão dos registros nos prontuários, em todos os turnos de trabalho (manhã, tarde e noturno) nos meses de novembro de 2009 e janeiro de 2010. A definição do período de coleta baseou-se na dinâmica e característica da unidade, considerando-se a taxa de ocupação, tempo médio de permanência e média de pacientes/dia.

A observação diária ocorreu em períodos e horários predeterminados, nos turnos da manhã (10 às 11 horas), tarde (15 às 16 horas) e noturno (21 às 22 horas), considerando-se a rotina da unidade. Desta forma, cada paciente foi observado três vezes ao dia, desde o momento de sua internação até seu desfecho clínico, ou seja, alta, transferência ou óbito na unidade, constituindo-se este processo na etapa 2 deste estudo.

Para verificar o ângulo de inclinação da cabeceira da cama, foi utilizado um aparelho goniômetro que estava fixado às cabeceiras das camas ou era igualmente fixado pelas observadoras.

O prontuário dos pacientes também foi revisado com o objetivo de registrar a ocorrência de PAVM nos sujeitos da pesquisa.

Os dados foram coletados pela pesquisadora com 0 auxilio de três enfermeiras com experiência em terapia intensiva, que foram devidamente treinadas 
para o procedimento de coleta de dados e passaram a ser denominadas de avaliadores.

\subsection{Capacitação dos pesquisadores de campo}

Os avaliadores deste estudo foram constituídos por quatro profissionais, a saber:

Avaliador 1 - autora deste estudo e enfermeira com experiência em terapia intensiva;

Avaliadores 2, 3 e 4 - enfermeira com experiência em terapia intensiva.

Inicialmente foi realizada uma leitura exaustiva da estrutura do instrumento, para minimizar as dificuldades de compreensão ou dúvidas quanto aos itens de sua composição. Em seguida procedeu-se à aplicação junto aos pacientes, em caráter experimental durante 15 dias, de maneira a garantir a confiabilidade dos dados coletados. Os dados coletados nesta fase experimental não foram incluídos na pesquisa.

Polit, Beck e Hungler (2004) definem que a confiabilidade pode ser avaliada levando-se em conta três aspectos: a estabilidade ou consistência todo o tempo; a equivalência ou consistência entre várias versões ou aplicações e a consistência interna ou homogeneidade que se refere à consistência dentro da escala ou instrumento.

Neste estudo ressaltamos o aspecto da equivalência, método este que pode ser determinado pela utilização do instrumento por observadores diferentes, para mensuração dos mesmos fenômenos. Este é comumente referido como confiabilidade entre avaliadores.

A confiabilidade de um instrumento de avaliação relaciona-se com a consistência apresentada nos resultados obtidos quando diferentes enfermeiros aplicam o instrumento em diferentes pacientes.

$\mathrm{Na}$ confiabilidade entre avaliadores é possível verificar o grau de correspondência entre as avaliações independentes de dois ou mais enfermeiros que avaliam o mesmo paciente, utilizando o mesmo instrumento. Entretanto, como os instrumentos de avaliação não trazem em si mesmos, uma confiabilidade preestabelecida, de modo que possam ser utilizados em diferentes locais, torna-se 
necessário monitorar rotineiramente a sua aplicação (PERROCA; GAIDZINSK, 2004).

Assim, durante quinze dias, após a coleta independente entre as enfermeiras, procedia-se em seguida à conferência dos dados, comparando-os ao do pesquisador. À medida que neste confronto, eram detectadas divergências, estes dados eram discutidos e checados junto aos pacientes, quando necessário, até se obter o consenso entre os avaliadores. Estes foram considerados padronizados quanto ao preenchimento do instrumento no momento em que se obteve um nível de concordância acima de $90 \%$, assegurando deste modo a confiabilidade do processo de coleta de dados.

\subsection{Aspectos éticos}

Para a viabilização deste estudo, o mesmo foi encaminhado inicialmente à Diretoria Médica da UTI e Coordenação de Enfermagem da Unidade de Emergência do Hospital das Clínicas da Faculdade de Medicina de Ribeirão Preto/USP (HCFMRP) e em seguida à Coordenadoria do Centro de Estudos da unidade, solicitando permissão para o desenvolvimento da pesquisa. A seguir, enviado para apreciação do Comitê de Ética em Pesquisa do HCFMRP e Faculdade de Medicina de Ribeirão Preto (FMRP-USP) sendo aprovado e registrado sob o Processo HCRP no 11193/2008. Este estudo foi desenvolvido de modo a garantir o cumprimento dos preceitos da Resolução 196/96 do Comitê Nacional de Ética em Pesquisa (BRASIL, 1996).

Considerando a impossibilidade do paciente decorrente de sua condição de saúde, foram contatados e consultados os familiares sobre a possibilidade de participação no estudo. Mediante a concordância, o Termo de Consentimento Livre e Esclarecido (APÊNDICE C) foi apresentado para obtenção da autorização e sua inclusão.

\subsection{Análise dos dados}

Os dados referentes à avaliação foram digitados e armazenados em banco de dados e analisados quantitativamente pelo programa Epilnfo, versão 3.1.15, cujos resultados foram apresentados por meio de estatística descritiva. 
Para cálculo dos índices de conformidade das práticas incluídas no indicador aplicado, foram utilizadas as fórmulas recomendadas no construto operacional, de dois modos: conformidade geral do indicador e conformidade de cada componente avaliado. Assim:

Conformidade geral:

IRPR: Indicador de avaliação da adesão às medidas de prevenção e controle de pneumonia em pacientes de alto risco.

№ total de pacientes sob assistência ventilatória e com rebaixamento de consciência e/ou nutrição por sondas digestivas em que todos os componentes de controle para pneumonia hospitalar estão corretamente aplicados

№ total de pacientes avaliados, sob as condições descritas no numerador

Conformidade de cada componente do indicador:

Foi aplicada, isoladamente, a mesma forma de cálculo de conformidade, porém para cada componente do indicador. 
5 Resultados 
Durante o período do estudo, internaram 114 pacientes nas UTI observadas. Foram avaliados 38 pacientes sendo 26 (68,42\%) do sexo masculino e 12 (31,58\%) do sexo feminino com idade mínima de 19 e máxima de 82 anos. A distribuição dos pacientes por sexo e faixa etária está disposta na Tabela 1.

Excluiu-se do estudo 76 (66,67\%) pacientes. Destes $30(39,47 \%)$ estavam sem cânula orotraqueal (COT) e 31 (40,79\%) apresentavam diagnóstico médico de PNM no momento da admissão na referida UTI, não preenchendo, assim, os critérios de inclusão, conforme disposto na Tabela 1.

Apesar de preencherem os critérios de inclusão, outros 15 (19,74\%) pacientes foram excluídos por não concordância (5) ou ausência (2) da família, paciente com pneumonia após 24 horas da internação (3), admissão e óbito no intervalo da coleta de dados (2), paciente extubou-se na admissão (1), paciente desconhecido (1) ou detento (1).

A Tabela 1 também apresenta dados que se referem ao tempo de internação, onde observou-se que este, anterior à UTI variou entre 2 horas até 33 dias. O tempo mínimo de internação dos pacientes na unidade estudada foi de 1 dia e o tempo máximo de 28 dias.

Tabela 1 - Distribuição dos pacientes com ventilação mecânica de um hospital público, segundo as variáveis idade e tempo de permanência na Unidade de Terapia Intensiva (UTI), por sexo, Ribeirão Preto, 2009-2010

\begin{tabular}{lccc}
\hline \multirow{2}{*}{ Variáveis } & \multicolumn{3}{c}{ Sexo } \\
\cline { 2 - 4 } & $\begin{array}{c}\text { Feminino } \\
\mathrm{n}(\%)\end{array}$ & $\begin{array}{c}\text { Masulino Total n }(\%) \\
\mathrm{n}(\%)\end{array}$ \\
\hline Faixa etária (anos completos) & $1(12,50)$ & $7(87,50)$ & $8(21,05)$ \\
$19-29$ & $3(27,27)$ & $8(72,73)$ & $11(28,95)$ \\
$30-39$ & $2(50,00)$ & $2(50,00)$ & $4(10,53)$ \\
$40-49$ & $3(60,00)$ & $2(40,00)$ & $5(13,16)$ \\
$50-59$ & $2(28,57)$ & $5(71,43)$ & $7(18,42)$ \\
$60-69$ & $1(33,33)$ & $2(66,67)$ & $3(7,89)$ \\
$70-82$ & $12(31,58)$ & $26(68,42)$ & $38(100,0)$ \\
\hline Total & & & \\
\hline Tempo de Permanência na UTI (dias) & $4(23,53)$ & $13(76,47)$ & $17(44,74)$ \\
$1-7$ & $6(42,86)$ & $8(57,14)$ & $14(36,84)$ \\
$8-14$ & $1(33,33)$ & $2(66,66)$ & $3(7,89)$ \\
$9-21$ & $1(25,00)$ & $3(75,00)$ & $4(10,53)$ \\
$22-28$ & \multicolumn{3}{c}{$38(100,00)$} \\
\hline Total & \multicolumn{3}{c}{} \\
\hline
\end{tabular}


Os dados referentes ao local de internação prévio e destino pós internação na UTI dos pacientes estudados estão apresentados na Tabela 2.

Tabela 2 - Distribuição dos pacientes com ventilação mecânica de um hospital público, segundo as unidades de internação prévia e pós Unidade de Terapia Intensiva (UTI), Ribeirão Preto, 2009-2010

\begin{tabular}{lcccc}
\hline Unidades de & \multicolumn{2}{c}{ Prévia à UTI } & \multicolumn{2}{c}{ Pós-UTI } \\
\cline { 2 - 5 } Internação & $\mathbf{n}$ & $\%$ & $\mathrm{n}$ & $\%$ \\
\hline Sala de Politrauma & 8 & 21,05 & $\ldots$ & $\ldots$ \\
Sala de Estabilização Clínica & 8 & 21,05 & $\ldots$ & $\ldots$ \\
Sala de Recuperação & 11 & 28,95 & $\ldots$ & $\ldots$ \\
Centro Cirúrgico & 5 & 13,16 & $\ldots$ & $\ldots$ \\
Semi-intensivo & 3 & 7,90 & 3 & 7,90 \\
Sala de Urgência & 1 & 2,63 & $\ldots$ & $\ldots$ \\
UCO & 1 & 2,63 & $\ldots$ & $\ldots$ \\
Enfermaria & 1 & 2,63 & 13 & 34,20 \\
Transferência para outro Hospital & $\ldots$ & $\ldots$ & 3 & 7,90 \\
UTI & $\ldots$ & $\ldots$ & 3 & 7,90 \\
Óbito & $\ldots$ & $\ldots$ & 16 & 42,10 \\
\hline Total & 38 & 100,00 & 38 & 100,00 \\
\hline
\end{tabular}

Nota-se que 16 pacientes admitidos vieram do Bloco Cirúrgico, sendo que 11 $(28,95 \%)$ da Sala de Recuperação e 5 (13,16\%) diretamente do Centro Cirúrgico. Oriundos da Sala de Politrauma vieram 8 (21,05\%) pacientes. Observa-se, portanto, a prevalência dos pacientes jovens e do sexo masculino, refletindo a característica da população atendida nesta instituição com predominância de pacientes póscirúrgicos e politraumatizados.

Constatou-se que 19 pacientes receberam alta da unidade, 3 (7,89\%) continuavam internados na UTI ao término da coleta de dados e 16 pacientes evoluíram para óbito, correspondendo a $42,10 \%$ dos pacientes participantes do estudo. Estes valores diferem dos valores de risco de óbito calculados pelo APACHE II, em que a média percentual obtida foi de 11,86\%, conforme apresentados na Tabela 3. 
Tabela 3 - Distribuição de pacientes segundo média do valor do APACHE II e do risco de óbito e desfecho do caso, Ribeirão Preto, 2009-2010

\begin{tabular}{lccc}
\hline Variáveis & Pacientes & $\begin{array}{c}\text { Média Valor } \\
\text { APACHE II }\end{array}$ & $\begin{array}{c}\text { Média Risco de } \\
\text { Óbito }\end{array}$ \\
\hline Alta/Permanência na UTI & $22(57,89 \%)$ & 11,50 & 10,15 \\
Óbito & $16(42,10 \%)$ & 9,82 & 14,21 \\
\hline Total & $38(100 \%)$ & 10,53 & 11,86 \\
\hline
\end{tabular}

Foram realizadas 839 observações, relacionadas às medidas de prevenção e controle de PAVM conforme indicador IRPR, com os 38 sujeitos da pesquisa.

O número de observações realizadas por turno de trabalho foi de 277 para cada um dos turnos da manhã e tarde e 285 no turno da noite. Esta diferença foi devido às internações e altas que ocorreram após o horário estabelecido para coleta, aumentando, assim, as oportunidades de observação no turno da noite.

Todos os pacientes observados utilizavam COT sob ventilação mecânica e apresentavam rebaixamento do nível de consciência (38 pacientes), porém a presença de SNG/SNE foi identificada em 37 pacientes.

Ressalta-se que, em razão das práticas e responsabilidade pelo tipo de atividades sob avaliação, foram observadas apenas as atuações das equipes de enfermagem e fisioterapia.

São apresentadas, a seguir, as conformidades e não conformidades para cada prática avaliada e associações entre os turnos de trabalho.

A avaliação da adesão às medidas específicas de prevenção e controle de PAVM pelo indicador IRPR foi composta de quatro medidas, a saber: troca de material de terapia respiratória respeitando a rotina estabelecida no local do estudo, fisioterapia respiratória diária, cabeceira elevada a 30-45으 e uso de soluções estéreis para nebulizador e inalador.

É importante ressaltar que, para o cálculo de conformidade geral, conforme fórmula do indicador IRPR considerou-se o total de observações em que todas as medidas estavam em conformidade no mesmo paciente. Deste modo, bastava apenas uma das quatro medidas não estar corretamente aplicada para que a conformidade naquele paciente não fosse obtida. Os resultados são apresentados na Tabela 4. 
Tabela 4 - Distribuição das observações dos pacientes de um hospital público, com respectivos percentuais de conformidade geral, por turno de trabalho, das medidas específicas de prevenção e controle de pneumonia associada à ventilação mecânica, Ribeirão Preto, 2009-2010

\begin{tabular}{lccc}
\hline \multirow{2}{*}{ Turno de Trabalho } & \multirow{2}{*}{ Total } & \multicolumn{2}{c}{ Conformidade } \\
\cline { 3 - 4 } & & $\mathbf{n}$ & $\mathbf{\%}$ \\
\hline Manhã & 277 & 64 & 23,10 \\
Tarde & 277 & 36 & 13,00 \\
Noite & 285 & 126 & 44,21 \\
\hline Total & 839 & 226 & 26,94 \\
\hline
\end{tabular}

A conformidade geral a todas as medidas de prevenção e controle de PAVM correspondeu a $26,94 \%$. O turno da noite foi o que apresentou índice maior $(44,21 \%)$ e o da tarde, o índice menor (13,00\%).

A Tabela 5 permite reconhecer conformidade e não conformidade a cada medida específica de prevenção e controle de PAVM, assim como os turnos de trabalho.

Tabela 5 - Total de observações e índices de conformidade e não conformidade de cada medida específica de controle e prevenção de pneumonia associada à ventilação mecânica, por turno de trabalho, Ribeirão Preto, 2009-2010

\begin{tabular}{|c|c|c|c|c|c|}
\hline \multirow{2}{*}{ Variáveis } & \multirow{2}{*}{ Total } & \multicolumn{2}{|c|}{ Conformidade } & \multicolumn{2}{|c|}{ Não Conforme } \\
\hline & & $n$ & $\%$ & $\mathbf{n}$ & $\%$ \\
\hline \multicolumn{6}{|l|}{ Manhã } \\
\hline Uso de Solução estéril & 277 & 276 & 99,64 & 1 & 0,36 \\
\hline $\begin{array}{l}\text { Troca de material de } \\
\text { terapia respiratória }\end{array}$ & 277 & 261 & 94,22 & 16 & 5,78 \\
\hline Atendimento Fisioterapia & 277 & 124 & 44,76 & 153 & 55,24 \\
\hline Cabeceira elevada $30-45^{\circ}$ & 275 & 143 & 52,00 & 132 & 48,00 \\
\hline Subtotal manhã & 1106 & 804 & 72,69 & 302 & 27,31 \\
\hline \multicolumn{6}{|l|}{ Tarde } \\
\hline Uso de Solução estéril & 277 & 277 & 100,00 & 0 & 0 \\
\hline $\begin{array}{l}\text { Troca de material de } \\
\text { terapia respiratória }\end{array}$ & 277 & 262 & 94,58 & 15 & 5,42 \\
\hline Atendimento Fisioterapia & 277 & 86 & 31,05 & 191 & 68,95 \\
\hline Cabeceira elevada $30-45^{\circ}$ & 269 & 127 & 47,21 & 142 & 52,79 \\
\hline Subtotal tarde & 1100 & 752 & 68,36 & 348 & 31,64 \\
\hline \multicolumn{6}{|l|}{ Noite } \\
\hline Uso de Solução estéril & 285 & 284 & 99,65 & 1 & 0,35 \\
\hline $\begin{array}{l}\text { Troca de material de } \\
\text { terapia respiratória }\end{array}$ & 285 & 275 & 96,49 & 10 & 3,51 \\
\hline Atendimento Fisioterapia & & $\ldots$ & $\ldots$ & $\ldots$ & $\ldots$ \\
\hline Cabeceira elevada $30-45^{\circ}$ & 281 & 130 & 46,26 & 151 & 53,74 \\
\hline Subtotal noite & 851 & 689 & 80,96 & 162 & 19,04 \\
\hline Total & 3057 & 2245 & 73,44 & 812 & 26,56 \\
\hline
\end{tabular}

*No período noturno não há fisioterapia 
A manutenção da cabeceira elevada foi outro item que não atingiu a conformidade esperada, repetindo-se nos três turnos, sendo que o turno da noite obteve menor conformidade (46,26\%).

Verifica-se, ainda, que cada medida isoladamente obteve índice de conformidade sempre superior ao da conformidade geral $(26,94 \%)$, o qual associou todas as medidas por paciente. A manutenção da cabeceira elevada e o atendimento de fisioterapia foram as medidas que mais influenciaram negativamente na obtenção dessa conformidade geral.

O uso de solução estéril e a troca de material de terapia respiratória obtiveram os índices mais altos de conformidade, em alguns casos, atingiram a totalidade (100\%).

A Tabela 6 apresenta as não conformidades segundo cada turno de trabalho.

Tabela 6 - Índices de não conformidade de cada medida específica de controle e prevenção de pneumonia associada à ventilação mecânica, segundo o turno de trabalho, Ribeirão Preto, 2009-2010

\begin{tabular}{lcccc}
\hline \multirow{2}{*}{ Variáveis } & \multicolumn{4}{c}{ Turno de Trabalho } \\
\cline { 2 - 5 } & $\begin{array}{c}\text { Manhã } \\
\mathbf{n}(\%)\end{array}$ & $\begin{array}{c}\text { Tarde } \\
\mathbf{n}(\%)\end{array}$ & $\begin{array}{c}\text { Noite } \\
\mathbf{n}(\%)\end{array}$ & $\begin{array}{c}\text { Total } \\
\mathbf{n}(\%)\end{array}$ \\
\hline Cabeceira elevada 30-45 & $132(43,71)$ & $142(40,80)$ & $151(93,21)$ & $4245(52,34)$ \\
Atendimento fisioterapia & $153(50,66)$ & $191(54,89)$ & - & $344(42,36)$ \\
Troca de material de & $16(5,30)$ & $15(4,31)$ & $10(6,17)$ & $41(5,05)$ \\
terapia respiratória & $1(0,33)$ & & $1(0,62)$ & $2(0,25)$ \\
Uso de solução estéril & $302(100)$ & $348(100)$ & $162(100)$ & $812(100)$ \\
\hline Total & & &
\end{tabular}

*No período noturno não há fisioterapia

A cabeceira elevada, medida que obteve uma das menores conformidades nos três turnos devido ao posicionamento abaixo do ângulo recomendado (30-459), foi a principal responsável pela não conformidade geral obtida, principalmente no turno da noite $(93,21 \%)$.

A fisioterapia respiratória realizada somente nos turnos manhã e tarde, correspondeu à segunda maior frequência de não conformidade (42,36\%), sendo constatado maior índice de não conformidade no turno da tarde $(54,89 \%)$.

Quanto à troca de material de terapia respiratória, o turno da manhã apresentou maior não conformidade (16 casos). 
Ressalta-se que a avaliação dessas medidas realizou-se mediante averiguação da aplicabilidade para cada paciente, nos períodos previstos de observação, portanto, não foi possível associá-las com as categorias profissionais.

Pela análise dos prontuários médicos identificou-se que 13 (34,21\%) pacientes desenvolveram PAVM durante a internação, sendo 10 (76,92\%) do sexo masculino e $3(23,08 \%)$ do sexo feminino. A Tabela 7 demonstra esta distribuição.

Tabela 7 - Distribuição dos pacientes com ventilação mecânica de um hospital público, por sexo, segundo a presença de pneumonia associada à ventilação mecânica, Ribeirão Preto, 2009-2010

\begin{tabular}{|c|c|c|c|c|}
\hline Pneumonia & Sexo & Masculino & Feminino & Total \\
\hline Sim & & 10 & 3 & $13(34,21 \%)$ \\
\hline Não & & 16 & 9 & $25(65,79 \%)$ \\
\hline Total & & $26(68,42 \%)$ & $12(31,58 \%)$ & $38(100 \%)$ \\
\hline
\end{tabular}

Dentre eles, 5 pacientes desenvolveram PAVM em até 96 horas de internação. A Tabela 8 apresenta a distribuição de quantos dias após a internação na UTI os pacientes desenvolveram PAVM e o tempo de internação destes pacientes na unidade.

Tabela 8 - Pacientes com ventilação mecânica que apresentaram pneumonia segundo tempo de internação e tempo de aparecimento da morbidade, Ribeirão Preto, 2009-2010

\begin{tabular}{ccc}
\hline Variáveis & $\begin{array}{c}\text { Dias após } \\
\text { internação }\end{array}$ & $\begin{array}{c}\text { Dias de } \\
\text { internação }\end{array}$ \\
\hline Paciente 1 & 4 & 26 \\
Paciente 2 & 9 & 14 \\
Paciente 3 & 9 & 18 \\
Paciente 4 & 4 & 9 \\
Paciente 5 & 14 & 14 \\
Paciente 6 & 10 & 28 \\
Paciente 7 & 5 & 27 \\
Paciente 8 & 4 & 27 \\
Paciente 9 & 7 & 12 \\
Paciente 10 & 5 & 20 \\
Paciente 11 & 4 & 7 \\
Paciente 12 & 4 & 7 \\
Paciente 13 & 7 & 12 \\
\hline
\end{tabular}


Uma comparação entre os pacientes que desenvolveram PAVM, valor e risco de óbito calculados pelo APACHE II, desfecho do caso e conformidade ao indicador IRPR pode ser feita a partir dos dados demonstrados na Tabela 9. Salienta-se que o índice de conformidade total apresentado refere-se ao período total de internação deste paciente.

Tabela 9 -Pacientes com ventilação mecânica que apresentaram pneumonia segundo os índices de conformidade geral e prévia à morbidade, valor do APACHE II, risco de óbito e desfecho do caso, Ribeirão Preto, 2009-2010

\begin{tabular}{lccccc}
\hline Pacientes & $\begin{array}{c}\text { Conformidade } \\
\text { antes da PNM } \\
\text { (\%) }\end{array}$ & $\begin{array}{c}\text { Conformidade } \\
\text { Total (\%) }\end{array}$ & $\begin{array}{c}\text { Valor do } \\
\text { APACHE II }\end{array}$ & $\begin{array}{c}\text { Risco de } \\
\text { Óbito (\%) }\end{array}$ & Desfecho \\
\hline Paciente 1 & 42,86 & 33,33 & 9 & 18,54 & Alta \\
Paciente 2 & 32,00 & 28,13 & 12 & 26,08 & Alta \\
Paciente 3 & 12,5 & 15,15 & 12 & 7,22 & Alta \\
Paciente 4 & - & 12,50 & 8 & 13,61 & Alta \\
Paciente 5 & 17,86 & 5,88 & 12 & 12,46 & Alta \\
Paciente 6 & 5,88 & 15,39 & 10 & 20,85 & Alta \\
Paciente 7 & 33,33 & 23,73 & 12 & 12,46 & Alta \\
Paciente 8 & 45,45 & 40,91 & 12 & 8,39 & Alta \\
Paciente 9 & 38,10 & 37,50 & 9 & 4,92 & Alta \\
Paciente 10 & 38,46 & 25,42 & 12 & 12,46 & Óbito \\
Paciente 11 & 33,33 & 35,29 & 12 & 12,46 & Óbito \\
Paciente 12 & 10,00 & 15,79 & 11 & 9,42 & Óbito \\
Paciente 13 & 57,90 & 54,55 & 12 & 16,08 & Alta \\
\hline
\end{tabular}

NOTA: APACHE II - índice de gravidade (Acute Physiology and Chronic Health Evalution II)

Foram calculados os índices de conformidade e não conformidade de cada medida específica de prevenção e controle de PAVM e geral para este grupo de 13 pacientes observados no estudo e que desenvolveram esta infecção, buscando identificar uma possível relação com o resultado final, ou seja, o aparecimento de PAVM. Os dados apurados são aqueles referentes aos dias pré-diagnóstico e estão dispostos nas Tabelas 10 e 11. 
Tabela 10 - Índices da conformidade geral e por turno de trabalho das medidas específicas de prevenção e controle de pneumonia associada à ventilação mecânica para os pacientes que desenvolveram pneumonia ( $n=13)$, Ribeirão Preto, 2009-2010

\begin{tabular}{lccc}
\hline \multirow{2}{*}{ Turno de Trabalho } & \multirow{2}{*}{ Total } & \multicolumn{2}{c}{ Conformidade } \\
\cline { 3 - 4 } & & $\mathbf{n}$ & $\mathbf{\%}$ \\
\hline Manhã & 67 & 22 & 32,84 \\
Tarde & 68 & 8 & 11,76 \\
Noite & 76 & 28 & 36,84 \\
\hline Total & 211 & 58 & 27,49 \\
\hline
\end{tabular}

Tabela 11 - Total de observações e índices de conformidade e não conformidade de cada medida específica de controle e prevenção de pneumonia associada à ventilação mecânica para os pacientes que desenvolveram pneumonia $(n=13)$ segundo o turno de trabalho, Ribeirão Preto, 20092010

\begin{tabular}{|c|c|c|c|c|c|}
\hline \multirow{2}{*}{ Variáveis } & \multirow{2}{*}{ Total } & \multicolumn{2}{|c|}{ Conformidade } & \multicolumn{2}{|c|}{ Não Conforme } \\
\hline & & $\mathrm{n}$ & $\%$ & $\mathrm{n}$ & $\%$ \\
\hline \multicolumn{6}{|l|}{ Manhã } \\
\hline Uso de Solução estéril & 67 & 67 & 100,00 & _ & _ \\
\hline $\begin{array}{l}\text { Troca de material de } \\
\text { terapia respiratória }\end{array}$ & 67 & 63 & 94,03 & 4 & 5,97 \\
\hline Atendimento Fisioterapia & 67 & 43 & 64,18 & 24 & 35,82 \\
\hline Cabeceira elevada $30-45^{\circ}$ & 67 & 32 & 47,76 & 35 & 52,24 \\
\hline Subtotal manhã & 268 & 205 & 76,49 & 63 & 23,51 \\
\hline \multicolumn{6}{|l|}{ Tarde } \\
\hline Uso de Solução estéril & 68 & 68 & 100,00 & _- & _- \\
\hline $\begin{array}{l}\text { Troca de material de } \\
\text { terapia respiratória }\end{array}$ & 68 & 65 & 95,59 & 3 & 4,41 \\
\hline Atendimento Fisioterapia & 68 & 24 & 35,29 & 44 & 64,71 \\
\hline Cabeceira elevada $30-45^{\circ}$ & 67 & 26 & 38,81 & 41 & 61,19 \\
\hline Subtotal tarde & 271 & 183 & 67,53 & 88 & 32,47 \\
\hline \multicolumn{6}{|l|}{ Noite } \\
\hline Uso de Solução estéril & 76 & 76 & 100,00 & _- & _ \\
\hline $\begin{array}{l}\text { Troca de material de } \\
\text { terapia respiratória }\end{array}$ & 76 & 73 & 96,05 & 3 & 3,95 \\
\hline Atendimento Fisioterapia & $\ldots$ & $\ldots$ & $\ldots$ & $\ldots$ & $\ldots$ \\
\hline Cabeceira elevada $30-45^{\circ}$ & 74 & 27 & 36,49 & 47 & 63,51 \\
\hline Subtotal noite & 226 & 176 & 77,88 & 50 & 22,12 \\
\hline Total & 765 & 564 & 73,72 & 201 & 26,28 \\
\hline
\end{tabular}

*No período noturno não há fisioterapia 
Verifica-se que os valores apresentados são semelhantes àqueles identificados para todos os pacientes participantes deste estudo, independente do diagnóstico de PNM. 
6 Discussão 
Os serviços de terapia intensiva ocupam áreas hospitalares destinadas ao atendimento de pacientes críticos que necessitam de cuidados complexos e especializados. Esses serviços têm como objetivo: concentrar recursos humanos e materiais para o atendimento de pacientes graves que exigem assistência permanente, além da utilização de recursos tecnológicos apropriados para a observação e monitorização contínua das condições vitais do paciente e para a intervenção em situações de descompensações (PADILHA; KIMURA, 2000).

Entende-se que a UTI é uma unidade prioritária para o desenvolvimento e aplicação de indicadores de qualidade devido à demanda de inúmeros processos desenvolvidos com pacientes críticos e que, na maioria das vezes, dependem exclusivamente dos cuidados da equipe para sobreviver.

Neste sentido, para Fernandes et al (2000), as UTI são unidades sócio-técnicoestruturadas voltadas para a prestação da assistência individualizada aos pacientes críticos, gravemente enfermos, que devem ser devolvidos à sociedade de forma plena, sem terem sido colocados em situações de risco. Isto implica na utilização de novas tecnologias no processo de cuidar, indicando a necessidade, dentre outras coisas, de um conjunto de habilidades profissionais articuladas por ações e saberes direcionados para a qualidade do cuidado e seu gerenciamento.

As IH ou infecções adquiridas nos serviços de saúde (IASS) constituem risco significativo à saúde dos usuários e, deste modo, a sua prevenção e controle são de suma importância e envolvem medidas de qualificação da assistência hospitalar através de ações que implementam a melhoria da qualidade da assistência à saúde, reduzindo esforços, complicações e recursos.

Assim, faz-se necessário o gerenciamento da qualidade no âmbito hospitalar com vistas a alcançar um padrão aceitável de assistência e atender às expectativas dos trabalhadores e pacientes.

Apesar dos estudos científicos, guias clínicos, diretrizes e regulamentações governamentais existentes ainda é um desafio reduzir a ocorrência das IASS. No entanto, o gerenciamento das ações de prevenção e controle ajuda os serviços/gerentes a reconhecerem se e como esses recursos estão sendo incorporados na prática assistencial, isto é, se estas ações estão sendo cumpridas nos diversos âmbitos da instituição. 
Observou-se, dentre os dados coletados no presente estudo, que 13 (34,21\%) pacientes desenvolveram PAVM e que, em 5 (38,46\%) pacientes, a PAVM foi diagnosticada com 96 horas de internação na UTI.

Esses valores são condizentes aos encontrados na literatura. Estudo de prevalência de infecção hospitalar realizado em instituições com mais de 100 leitos, nas capitais estaduais brasileiras, identificou que 42,9\% dos pacientes em terapia intensiva são acometidos por infecções respiratórias (PRADE et al., 1995).

Identifica-se em dados norte-americanos que 9 a 27\% dos pacientes submetidos a intubação traqueal desenvolvem PNM em algum momento de sua internação (RELLO et al., 2002).

Gusmão et al (2004) realizaram estudo de coorte em UTI de hospital universitário e observaram que $11,8 \%$ dos pacientes admitidos desenvolveram PNM nosocomial (75\% dos pacientes internados usavam VM) com 72 horas após a admissão. Em outro estudo que objetivou determinar a prevalência de PAVM, em UTI, 38,1\% dos pacientes desenvolveram PAVM em aproximadamente quatro dias (96 horas) (GUIMARÃES; ROCO, 2006).

Dados obtidos junto a hospitais de médio e grande porte associados ao Consórcio Internacional para Controle das Infecções Hospitalares revelaram que, em média, 13,2\% dos pacientes admitidos em UTI nestas instituições adquirem PAVM (SALOMÃO, et al., 2008).

Segundo Rodrigues (2009), dados coletados na UTI de um hospital terciário e de ensino pela Comissão de Controle de Infecção Hospitalar (CCIH), no período de 1999 a 2005, indicaram o trato respiratório como a infecção mais frequente de $\mathrm{IH}$ em 58 $(69,05 \%)$ dos 84 meses deste período e que a densidade média de PAVM foi de 21,8 episódios por 1000 dias de ventilação mecânica.

Para Gusmão, Dourado e Fiaccone (2004), o risco de infecção é diretamente proporcional à gravidade da doença, às condições nutricionais e imunológicas do paciente, ao tempo de internação, à natureza dos procedimentos diagnósticos e/ou terapêuticos, entre outros aspectos. Neste sentido, outro dado relevante encontrado no presente estudo foi o número de pacientes que evoluíram para óbito (42,1\%). Para fins de comparação foi calculado um índice de avaliação prognóstica APACHE II dos pacientes incluídos no estudo.

As médias dos valores do APACHE II e risco de óbito encontrados foram 10,53 e 11,86\%, respectivamente, para os pacientes com evolução para óbito. Assim, nota-se 
diferença entre o risco de óbito e o óbito observado na população em estudo. A literatura traz valores diferentes.

Zeitoun et al (2001) calcularam o APACHE II nos pacientes submetidos a ensaio clinico randomizado com objetivo de identificar a incidência de PAVM em pacientes submetidos à aspiração traqueal pelos sistemas aberto e fechado e encontraram média de valores 20,83 e 20,37 para os dois grupos, respectivamente.

Teixeira et al (2004) encontraram valores entre 19,4 e 22,7 em pacientes com PAVM por micro-organismos sensíveis e resistentes à antibioticoterapia.

Baxter et al (2005), em estudo que analisou a introdução de três novas medidas de prevenção ao protocolo de redução de incidência de PAVM em cinco UTI de um mesmo hospital, encontraram nos dados de caracterização dos pacientes, risco de óbito entre $29,6 \%$ e $35,1 \%$.

De acordo com o Manual de Indicadores de Avaliação da Qualidade de Práticas de Controle de Infecção Hospitalar (SÃO PAULO, 2006), um sistema de avaliação e qualificação do controle e prevenção de IASS, precisa atualizar-se constantemente, incorporando novas práticas e abordagens que deem conta da dinamicidade da evolução da assistência clínica e de novas evidências científicas.

O gerenciamento da assistência permite avaliar a implementação das recomendações, ou seja, trata-se de visualizar como a ação se comporta na prática (LACERDA; JOUCLAS; ENGRY, 1996). Para tanto, pode-se lançar mão de instrumentos que permitam avaliar a conformidade dos cuidados prestados.

O presente estudo procurou, também, atender ao desafio da busca por novos sistemas de avaliação da qualidade da assistência prestada pelo serviço de saúde, voltados às práticas de controle e prevenção da PAVM, por meio da aplicação de um indicador clínico de avaliação processual na UTI adulto de um hospital público de ensino, nos três turnos de trabalho (manhã, tarde e noite), referente à adesão a medidas específicas de controle e prevenção da PAVM (Indicador IRPR).

O referido indicador estava previamente construído e validado quanto ao seu conteúdo no manual de avaliação da qualidade de práticas de controle de prevenção de infecção hospitalar, disponibilizado pela Divisão de Infecção Hospitalar do Centro de Vigilância Epidemiológica da Secretária da Saúde do Estado de São Paulo (SÃO PAULO, 2006).

A maneira original desse indicador, na forma de construtor operacional e sob fundamentações teóricas-científicas, permite orientar tanto a aplicação da avaliação, 
quanto obter índices de conformidades com relação às melhores recomendações disponíveis (MENEZES, 2009).

Neste estudo, as avaliações exigiram predominantemente a observação direta (OD), conforme aplicações orientadas pelo indicador, nos períodos correspondentes ao tempo de observação, realizada nos três turnos de trabalho - entre 10 e 11 horas, 15 e 16 horas e 21 e 22 horas.

A OD exigiu averiguação da manutenção das medidas de elevação da cabeceira a 30-45, uso de solução estéril nos umidificadores dos ventiladores mecânicos e rotina de troca de material de terapia respiratória, quando observou-se os circuitos do ventilador mecânico que, conforme protocolo da $\mathrm{CCH}$ da instituição, devem ser trocados somente em caso de sujidade visível com sangue ou secreções. A avaliação do atendimento de fisioterapia respiratória consistiu da averiguação de seu registro no prontuário.

Mesmo que a não informação prévia das práticas sob observação possa gerar desconforto, tal método constitui a melhor oportunidade de reconhecimento das condições de sua realização, favorecendo ou desfavorecendo sua conformidade. Além disso, é um direito de segurança do paciente, a melhoria contínua de ações assistenciais, que somente podem ocorrer pelo reconhecimento daquelas que não apresentam conformidade com melhores evidências disponíveis.

É importante relatar que o grupo de observadoras não encontrou dificuldade no acesso às informações ou resistência da equipe em desenvolver as atividades rotineiras durante o período de observação, portanto é pertinente afirmar que os dados retratam a realidade da UTI em questão.

Uma questão intrigante e ainda pouco discutida na aplicação deste método se refere a não possibilidade de intervenção no momento em que uma dada prática é realizada incorretamente (MENEZES, 2009).

No entanto, a evidência da relevância deste método (OD) de obtenção de informações foi demonstrada nos resultados deste estudo. Apesar disso, foi possível reconhecer, com maior especificidade, questões sobre recursos de infraestrutura, processo de trabalho e necessidade de treinamento em serviços. Tal reconhecimento dirige-se às categorias de fisioterapia e enfermagem, porque constituíram as equipes cujas práticas foram avaliadas.

Reportando-se à prática do indicador IRPR, composta de quatro medidas (adesão à troca de material de terapia respiratória, atendimento de fisioterapia 
respiratória, cabeceira elevada a 30-45ํㅡㄹ uso de soluções estéreis para nebulizador e inalador), foram realizadas 839 avaliações, sendo 277 no turno da manhã, 277 no turno da tarde e 285 no turno da noite.

Utilizando-se a fórmula para cálculo de conformidade desse indicador, que considera a somatória das quatro medidas corretas ao mesmo tempo e em um mesmo paciente, obteve-se índice de conformidade geral de $26,94 \%$. Houve variação entre os turnos, uma vez que a maior conformidade foi de $44,21 \%$ no turno da noite e a menor, $13 \%$ no turno da tarde.

Este resultado diverge do estudo realizado por Menezes (2009) em UTI adulto de um hospital público de ensino, quando foram aplicadas 3 unidades de processo para avaliar as práticas de controle e prevenção de PAVM, incluindo o indicador IRPR, utilizado no presente estudo, e obteve-se conformidade geral de $68 \%$, porém abaixo daquele esperado pela autora (80\%).

Vários questionamentos emergem frente a estes resultados, como, por exemplo, se as equipes avaliadas não têm conhecimento suficiente sobre a importância dessas medidas para prevenção de PAVM? O grande número de procedimentos e a gravidade dos pacientes ali internados desviam a atenção da equipe para outros cuidados mais urgentes?

É importante comentar que a CCIH tem papel relevante, dentro da UTI em estudo, no que se refere à capacitação dos profissionais sobre a adesão às medidas de prevenção de infecção e neste sentido, alguns meses antes do início da coleta de dados, foi realizado no hospital, um curso de atualização para equipe de enfermagem sobre as principais IASS e suas medidas preventivas, oferecido pela $\mathrm{CCIH}$.

Calculando as medidas, isoladamente, constatou-se que a "manutenção da cabeceira elevada a $30-45^{\circ}$ e o "atendimento de fis ioterapia respiratória" foram os principais responsáveis pela não obtenção da conformidade geral esperada, ao variar de $46,26 \%$ a $52 \%$ e $44,76 \%$ a $47,21 \%$, respectivamente.

As demais medidas obtiveram cada uma, conformidades acima da esperada entre os turnos. As medidas que superaram a conformidade esperada foram o uso de solução estéril que alcançou $100 \%$ no turno da tarde e a troca de material de terapia respiratória com conformidades entre $94,22 \%$ e 96,49\%, permitindo constatar que tais recomendações estão bem estabelecidas na assistência ao paciente em ventilação mecânica. 
As baixas conformidades de adesão à recomendação de cabeceira elevada a $30-45^{\circ}$ surpreenderam, uma vez que, a maioria das camas, possui um instrumento medidor conhecido como goniômetro instalado na lateral da cabeceira. Para rigor deste estudo, as observadoras posicionavam de modo semelhante, um goniômetro cedido pelo hospital (de mesma marca e modelo) na cabeceira das camas onde estes ainda não estavam disponíveis.

Ressalta-se, também, que, a manutenção da cabeceira elevada no grau adequado pode ser realizada por todos os profissionais da saúde que atuam na unidade, e tal procedimento demanda pouco tempo e esforço, quando comparados a outras medidas. Ressalta-se que, quando os pacientes foram submetidos a procedimentos que exigiam a redução do grau da cabeceira ou outras posições (supina, por exemplo), tais momentos não eram contabilizados.

Em relação às não conformidades relacionadas à cabeceira elevada, todas (424) se referiram a graus inferiores aos recomendados em todos os períodos $(43,71 \%$ manhã; 40,8\% - tarde; 93,21\% - noite). Os valores observados no goniômetro nestes casos não foram registrados, porém os observadores encontraram valores próximos de 20-25, em grande parte dos casos.

Este dado foi constado por Menezes (2009), com índices de não conformidade de $75 \%, 77,4 \%$ e $82,2 \%$ nos turnos manhã, tarde e noite, respectivamente. Tais resultados mostram que muitos profissionais não estão habituados a conferir a elevação da cabeceira a partir do goniômetro, restringindo-se apenas à própria impressão visual.

Segundo Cason et al (2007) pacientes criticamente enfermos frequentemente apresentam depressão do nível de consciência e reflexo de vômito prejudicado, levando a congregação de secreção contaminados na parte posterior da orofaringe. Assim, o benefício da manutenção da cabeceira elevada a 30- 45, consiste na redução do risco de refluxo e aspiração do conteúdo gástrico nos pacientes sob ventilação mecânica (GRAP; MUNRO, 1997).

Esta medida é parte do guia clínico para prevenção de pneumonia associada aos serviços de saúde dos Centers for Disease Control and Prevention Guidelines (CDC) como categoria II de evidência, que sugere sua aplicação em pacientes submetidos à VM e/ou uso de sonda enteral, desde 2003 (TABLAN et al, 2004; COFFIN et al, 2008) e embora represente medida não farmacológica, simples e de baixo custo, ela ainda carece de maior incorporação pelos profissionais da saúde envolvidos na prática assistencial (MENEZES, 2009; MIGUEL-ROIG et al, 2006; DRAKULOVIC et al, 1999). 
Drakulovic et al (1999), em ensaio clínico semelhante randomizado e controlado, evidenciaram que a posição supina (09), foi um fato $r$ de risco independente para 0 desenvolvimento de PAVM em pacientes sob VM hospitalizados em uma UTI médicocirúrgica, e que a posição semirecumbente (45) reduziu a frequência e o risco de desenvolver PAVM.

Em estudo qualitativo (grupo focal), Cook et al (2002) entrevistaram 93 trabalhadores de UTI de várias categorias profissionais a respeito da posição semirecumbente para prevenção de PAVM. Os participantes responderam que a posição usual do corpo para pacientes em VM era a supina ou com cabeceira elevada a $10-30^{\circ}$ e que fatores pulmonares e não pulmonares de terminavam a posição do paciente.

Outro estudo analisou a adesão dos enfermeiros às recomendações dos guias clínicos para prevenção de PAVM com aplicação de questionário distribuído em congresso anual europeu de enfermeiros que atuam em UTI. Participaram do estudo 51 enfermeiros, obtendo-se os seguintes resultados sobre a aderência às práticas de prevenção de PAVM: 96,8\% responderam que usavam luvas e aventais de proteção diante do risco de contaminação com material biológico, 88,5\% faziam fisioterapia respiratória nos pacientes, $84,3 \%$ acatavam rotina da instituição quanto à troca de circuito do ventilador mecânico, $76,4 \%$ posicionavam a cabeceira a 30-45\%, entre outras medidas (RICART et al, 2003).

A posição semirecumbente (30-459), foi recomendada por Dodek et al (2004), após revisão sistemática da literatura, devido a redução da incidência de PAVM e ser uma medida de baixo custo.

Foi encontrado também na revisão da literatura, um estudo que utilizou OD das medidas de prevenção e controle de PAVM na prática assistencial. Neste estudo, Baxter et al (2005) analisaram a introdução de três novas medidas de prevenção ao protocolo de redução de incidência de PAVM em cinco UTI de um mesmo hospital, junto às equipes médicas e de enfermagem. Antes da avaliação da frequência de adesão foi implantado um programa educacional para reforçar as antigas e novas recomendações, quanto à manutenção da cabeceira elevada a 30-45 (com aux ílio de um instrumento de medição dos graus de inclinação da cabeceira), alimentação enteral (transpilórica), dentre outras medidas. Ao longo de seis meses, as medidas resultaram em redução de 51,3\% nas taxas de PAVM, concluindo que a implementação e 
manutenção de um programa educacional, incluindo auditorias e retorno aos profissionais das informações obtidas, contribuíram para adesão a novo protocolo.

Estudo brasileiro teve como um de seus objetivos definir incidência de PAVM antes e após a implantação de protocolo para profilaxia de PNM que compreendeu a posição semirecumbente no leito, aspiração com técnica asséptica e intubação endotraqueal com paramentação e concluiu que a incidência de PAVM mostrou importante tendência ao declínio após implantação do protocolo de profilaxia, porém, sem significância estatística (CARMO NETO et al., 2006).

Van Nieuwenhoven et al (2006) comparam a posição semirecumbente (com cabeceira elevada a 459 e a prática padronizada (c abeceira 109 em UTI de 3 hospitais universitários em um estudo multicêntrico randomizado e controlado e concluíram que a elevação da cabeceira a $45^{\circ}$ graus não foi sistematicamente realizada e a di ferença de posicionamento entre os grupos experimental e controle $\left(28^{\circ}\right.$ e $10^{\circ}$, respectivamente) não preveniu a PAVM.

Em contra partida, Miguel-Roig et al (2006) recomendam esta medida, após concluir que a posição semirecumbente reduz incidência de PAVM.

Blot et al (2007) utilizaram um questionário de múltipla escolha distribuído em congresso de terapia intensiva, para avaliar o conhecimento sobre cuidados intensivos de guias clínicos recomendados para prevenção de PAVM. Dentre as várias questões da pesquisa e com participação expressiva de enfermeiros $(74,6 \%)$, obteve-se: o circuito do respirador deve ser trocado entre pacientes (49\%), a troca do umidificador do ventilador deve ser realizada uma vez por semana no mesmo paciente (13\%) e 90\% dos participantes conhecem a recomendação do posicionamento da cabeceira da cama do paciente em 30-45.

A implementação dos guias clínicos de PAVM publicados pelos CDC foi avaliada por Cason et al (2007) em estudo com 1200 enfermeiros que participaram de dois eventos educacionais nos EUA. Os resultados mostraram que $34 \%$ dos enfermeiros afirmaram manter a cabeceira da cama elevada a $30-45^{\circ}$ durante $75 \%$ do dia e $52 \%$ durante $100 \%$ do dia.

Os motivos da não adesão às práticas recomendadas em guias clínicos, segundo Ricart et al (2003), são inviabilidade de recursos (37\%), desconforto relatado pelo paciente $(8,2 \%)$, desacordo com os relatórios dos estudos $(7,8 \%)$ e receio de potenciais efeitos adversos $(5,8 \%)$. 
Outro estudo de revisão integrativa da literatura sobre as medidas preventivas de PAVM conclui que a posição semirecumbente do paciente (cabeceira elevada 459 parece participar na prevenção de PAVM, no entanto, surge a necessidade de mais estudos de nível I e II para recomendar esta medida com segurança e eficácia (BERALDO, 2008).

O papel do enfermeiro quanto à questão da avaliação clínica, manutenção e vigilância das medidas de prevenção e controle de infecções é de suma importância e têm relatos em literatura que comprovam esse tipo de assertiva. A importância dos enfermeiros na promoção da adesão à manutenção da cabeceira elevada a $30-45^{\circ}$ foi apontada por Krein et al (2008), após investigar quais práticas são usadas pelos hospitais para prevenção e controle de infecção em pacientes sob VM. Os dados obtidos mostraram que $83 \%$ dos hospitais usam a posição semirecumbente, $40 \%$ usam regularmente enxaguante bucal com antimicrobiano, $21 \%$ fazem regularmente aspiração da secreção subglótica e 18\% usam camas com terapia cinética. Compreende-se esta afirmação, uma vez que a enfermagem é maioria cuidadora nas instituições de saúde, comparando-se com outras categorias profissionais, permanecendo nas mesmas, durante as 24 horas do dia, realizando vários procedimentos com os pacientes nos diferentes turnos de trabalho, como banho, higiene íntima, curativos, aumentando as chances de reposicionamento do paciente.

Analisando os estudos citados, conclui-se que as conformidades variam muito, porém estão sempre acima daquelas encontradas no presente estudo. As baixas conformidades encontradas podem estar relacionadas ao uso incorreto do goniômetro e à ausência deste aparelho em alguns leitos, o que pode favorecer à adoção do nivelamento da cabeceira da cama pelos profissionais baseando-se apenas na impressão visual.

Outro item dos resultados encontrados se refere ao atendimento de fisioterapia que foi um dos principais responsáveis pela não obtenção da conformidade esperada $(42,36 \%)$, juntamente com a manutenção da cabeceira elevada (52,34\%) até aqui discutida.

A importância da fisioterapia na prevenção de PNM foi avaliada em estudo sistemático controlado, desenvolvido por Ntoumenopoulos et al (2002), que observaram que, a fisioterapia torácica foi independentemente associada com redução da ocorrência de PAVM, sugerindo o benefício desta técnica na prevenção de PAVM. 
Dodek et al (2004), em guia de prática clínica para prevenção de PAVM, concluiram que a fisioterapia torácica pode estar associada à redução da incidência de PAVM.

Miguel-Roig et al (2006) concluiram que não há evidência da efetividade das técnicas de percussão e vibração para prevenir PAVM.

A fisioterapia torácica também é recomendação feita por Jerre et al (2007), no III Consenso Brasileiro de Ventilação Mecânica, para prevenção de PAVM.

Identifica-se, portanto, que a fisioterapia respiratória, embora seja um atendimento necessário, não se constitui numa medida fortemente recomendada para prevenção de PAVM.

Identifica-se uma escassez de estudos sobre a adesão, pela equipe de fisioterapia, em relação a esta medida. A conformidade de 57,64\% alcançada neste estudo, entretanto está abaixo dos valores apresentados no estudo de Ricart et al (2003) que encontraram aderência dos enfermeiros à fisioterapia respiratória em 88,5\% dos casos. Cabe ressaltar que neste estudo os autores verificaram adesão a 19 medidas não farmacológicas de prevenção de PAVM, mas a população investigada foi de enfermeiros.

O atendimento de fisioterapia foi avaliado conforme registro em prontuário, de acordo com a orientação do IRPR. Deste modo, levantam-se alguns questionamentos: as não conformidades obtidas se referiram à ausência do registro de sua realização no prontuário do paciente por esquecimento ou a fisioterapia não foi realmente realizada? Será esta, a melhor técnica para avaliação desta medida? Menezes (2009) afirma ser a OD a técnica mais adequada para avaliação deste item, mas o tempo dispendido para observação teria que ser ampliado.

Ao analisar a conformidade encontrada de cada medida específica de prevenção e controle de PAVM antes da sua confirmação diagnóstica, conforme indicador IRPR, observou-se valores discrepantes de conformidade individual que variaram entre $0 \% \mathrm{e}$ $57,9 \%$ e a conformidade total durante a internação variou entre 5,88\% e 54,55\%.

A conformidade geral dos pacientes que desenvolveram PAVM foi de 27,49\%, discretamente maior que a conformidade geral de todos os pacientes (26,94\%).

A manutenção da cabeceira elevada e o atendimento de fisioterapia foram as principais medidas responsáveis pela não conformidade geral obtida para estes pacientes, fato que igualmente aconteceu com todos os pacientes. 
O atendimento de fisioterapia foi mais intenso no período da manhã (64,18\%). Já no período da tarde, a conformidade se assemelha àquela calculada para todos os pacientes do estudo.

A exemplo do que ocorreu no quadro geral dos pacientes, a medida que mais influenciou negativamente na obtenção da conformidade para os pacientes que desenvolveram PAVM foi a manutenção da cabeceira elevada, índice que obteve maior não conformidade no período noturno.

Os baixos índices de conformidade foram surpreendentes, pois se esperava que, por se tratar de um hospital de ensino, as medidas específicas aqui avaliadas para prevenção e controle de PAVM estivessem totalmente absorvidas pelos profissionais que ali atuam, pela relevância das mesmas e integradas à pratica diária.

Um aspecto que deveria ser inspecionado no processo de avaliação, em estudos dessa natureza, refere-se à identificação e descrição das situações de não conformidade das medidas específicas, que possibilitam o reconhecimento da não realização das práticas amplamente difundidas pela $\mathrm{CCIH}$ local e do guia clínico para prevenção de pneumonia associada aos serviços de saúde dos CDC e das orientações para prevenção de IASS da ANVISA. Isto pode possibilitar uma intervenção diretamente relacionada à situação identificada.

É importante, portanto, avaliar as diferenças entre teoria e prática e assim criar um plano de intervenção capaz de melhorar as estratégias educacionais e, consequentemente, a prática assistencial, possibilitando uma melhoria nos índices de conformidade uma vez que as ações tradicionais de vigilância epidemiológica, elaboração de normas e rotinas e treinamento em equipe não estão sendo suficientes. O envolvimento e integração do profissional da assistência com o grupo de controle de infecção é outra questão importante para gerar um sistema educacional de melhoria contínua.

Uma limitação do estudo refere-se à não avaliação de outros processos importantes para a prevenção de PAVM que podem ter impacto na redução da taxa de densidade de infecção e PAVM, como, por exemplo, a adesão à higiene das mãos e realização de higiene bucal, além de outros itens que não são amplamente recomendados, mas influenciam nestas taxas, como a avaliação da presença de condensado no circuito do respirador e avaliação da troca de filtros umidificadores, quando em uso, segundo a rotina da instituição. 
Desta maneira novos estudos são recomendados para ampliar a avaliação do processo de trabalho nesta unidade, bem como identificar motivos da não adesão pelos profissionais das medidas de prevenção e controle desta infecção. 
7 Considerações Finais 
As infecções respiratórias sempre foram bastante frequentes nos serviços de saúde no Brasil. Entre elas, a PNM destaca-se pela sua relevância como doença em si e comorbidades (ANVISA, 2009b).

Este estudo avaliou a conformidade de práticas de controle e prevenção da PAVM por meio da aplicação de um indicador de processo - Indicador de Avaliação da Adesão às Medidas de Prevenção e Controle de Pneumonia em Pacientes de Alto Risco (IRPR) - que possibilitou identificar os índices de adesão dessas práticas entre os turnos de trabalho e identificou o comportamento da adesão às medidas preventivas nos pacientes que desenvolveram PAVM.

O uso de indicadores para avaliar o desenvolvimento das IASS, em especial a PAVM, permite aos serviços de saúde quantificar problemas e oportunidades de melhoria. Assim, ao avaliar processos, pode-se encontrar um bom ou mau resultado. Deste modo, a conformidade alcançada neste estudo não foi satisfatória (26,94\%), embora algumas medidas isoladas que compõem o indicador IRPR tenham alcançado índices próximos a 100\%.

A manutenção da cabeceira da cama elevada a $30-45^{\circ}$ apresentou a menor conformidade em todos os turnos de trabalho avaliados, fato que demonstra a baixa atenção dispensada a esta recomendação tão simples e que demanda pouco tempo para ser realizada e a ausência de hábito dos profissionais em utilizar o instrumento goniômetro, localizado nas cabeceiras das camas, para verificar o grau correto. 0 atendimento de fisioterapia foi a segunda medida que apresentou menor conformidade.

Algumas medidas que foram analisadas pertencem às atividades realizadas rotineiramente pela enfermagem dentro da unidade, o que aponta para a necessidade de avaliação sistemática da intervenção de enfermagem nesta unidade. Isto envolve, além do processo educativo, a questão da supervisão e do gerenciamento do cuidado na unidade, uma vez que as normas, embora instituídas, nem sempre são seguidas na prática.

Os resultados encontrados dão abertura para que as ações de melhoria, como criação de novas estratégias educativas e a avaliação contínua do cuidado, possam ser discutidas e implantadas em grupo.

Recomenda-se que este tipo de avaliação possa ser utilizado pelos serviços por ser de fácil aplicação e passível de reprodução em outras instituições que tenham pacientes com estas características. 
ADAMI, N. P. A melhoria da qualidade nos serviços de enfermagem. Acta Paul. Enf., São Paulo, v. 13, pt 1, p. 190-6, 2000. Número Especial.

ADAMI, N. P.; YOSHITOME, A. Y. Métodos de avaliação de resultados da assistência de enfermagem. Rev. Bras. Enferm., Brasília, DF, v. 56, n. 1, p. 52-6, 2003.

ADAMI, N. P.; MARANHÃO, A. M. S. A. Qualidade dos serviços de saúde: conceitos e métodos avaliativos. Acta Paul. Enferm., São Paulo, v.8, n.4, p.47-55, mai./dez., 1995.

AMERICAN THORACIC SOCIETY; Infectious Diseases Society of America. Guidelines for the management of adults with hospital-acquired, ventilatorassociated, and healthcare-associated pneumonia. Am. J. Respir. Crit. Care Med., New York, v. 171, p. 388-416, Feb. 2005.

ANDREI, A. M. et al. Índices prognósticos em terapia intensiva. In: KNOBEL, E. Condutas no paciente grave. 3. ed. São Paulo: Atheneu, 2006. v. 1.

ANTUNES, A. V.; TREVIZAN, M. A. Gerenciamento da qualidade: utilização no serviço de enfermagem. Rev. Latino-am. Enferm., Ribeirão Preto, v. 8, n. 1, p. 3544 , jan. 2000.

AGÊNCIA NACIONAL DE VIGILÂNCIA SANITÁRIA (ANVISA). Unidade de Investigação e Prevenção das Infecções e dos Eventos Adversos. Gerência Geral de Tecnologia em Serviços de Saúde. Infecções do trato respiratório: orientações para prevenção de infecções relacionadas à assistência à saúde. Brasília, DF, out. 2009a. Disponível em: http://www.anvisa.gov.br/servicosaude/controle/manual \%20trato respirat\%F3rio.pdf . Acesso em: 25 abr. 2010.

- Unidade de Investigação e Prevenção das Infecções e dos Eventos Adversos. Gerência Geral de Tecnologia em Serviços de Saúde. Trato respiratório: critérios nacionais de infecções relacionadas à Assistência à Saúde. Brasília, DF, set. 2009b. Disponível em: http://www.anvisa.gov.br/servicosaude/controle/criterios infeccao trato respiratorio. pdf. Acesso em: 25 abr. 2010.

BITTAR, O. Indicadores de qualidade e quantidade em saúde. RAS, São Paulo, v. 3, n. 12, p. 21-8, 2001.

BADDER, B. Nursing cares behaviors that predict patient satisfaction. J. Nurs. Qual. Assur., Frederick, v. 2, n. 3, p. 11-7, 1998. 
BAXTER, A. D. et al. Adherence to simple and effective measures reduces the incidence of ventilator-associated pneumonia. Can. J. Anaesth., Toronto, v. 52, n. 5, p. 535-41, 2005.

BERALDO, C. C. Prevenção da pneumonia associada à ventilação mecânica: revisão integrativa. 2008. 160 f. Dissertação (Mestrado em Enfermagem) - Escola de Enfermagem de Ribeirão Preto, Universidade de São Paulo, Ribeirão Preto, 2008.

BLOT, S. I. et al. Executive Board of the Flemish Society for Critical Care Nurses. Evidence-based guidelines for the prevention of ventilator-associated pneumonia: results of a knowledge test among intensive care nurses. Intensive Care Med., New York, v. 33, n. 8, p. 1463-7, jun. 2007.

BORK, A. M. T. O desafio de mudar transformando as pessoas e a profissão: o sistema de enfermagem do Hospital Israelita Albert Einstein. Rev. Prat. Hosp., v. 6, n. 31, jan./fev. 2004. Disponível em: <http://www.praticahospitalar.com.br/pratica\%2031/paginas/materia\%2010-3.html $>$. Acesso em: 11 fev. 2010. .

BRASIL. Ministério da Saúde. Conselho Nacional de Saúde. Resolução 196: sobre diretrizes e normas regulamentadoras de pesquisa envolvendo seres humanos. Brasília, DF, 1996.

- Ministério da Saúde. Portaria no 2616/MS/GM de 12 de maio de 1998. Dispõe sobre o controle de infecção hospitalar. Diário Oficial da União, Brasília, DF, 13 de maio de 1998. Seção I, p. 133.

Ministério da Saúde. Secretaria de Políticas da Saúde. Departamento de Avaliação de Políticas de Saúde. Manual brasileiro de acreditação hospitalar. 2. ed. Brasília, DF, 1999.

BUSHNIK, T. et al. Etiology of traumatic brain injury: characterization of differential outcomes up to 1 year post injury. Arch. Phys. Med. Rehab., Chicago, v. 84, p. 255$62,2003$.

CARMO NETO, E. et al. Pneumonia associada à ventilação mecânica: análise de fatores epidemiológicos na confecção de estratégias de profilaxia e terapêutica. Rev. Bras. Ter. Intensiva, São Paulo, v. 18, n. 4, p. 344-50, dez. 2006.

CASON, C. L. et al. Nurses implementation of guidelines for ventilator-associated pneumonia from the Centers for Disease Control and Prevention. Am. J. Crit. Care., Aliso Viejo, v. 16, n. 1, p. 28-38, Jan. 2007. 
CIANCIARULLO, T. I. Administração da assistência de enfermagem. Uma questão de qualidade do cuidado. RPH, São Paulo v. 39, n. 9-12, 99-101, 103-8, set.-dez. 1991.

. C\&Q: teoria e prática em auditoria de cuidados. São Paulo: Ícone, 1997.

COFFIN, S. E. et al. Strategies to prevent ventilator-associated pneumonia in acute care hospitals. Infect. Control Hosp. Epidemiol., v. 29, p. S31-40, out. 2008. Suppl. 1. Disponível em: <http://www.journals.uchicago.edu/doi/pdf/10.1086/591062>. Acesso em: 20 nov. 2009.

COOK, D. J. et al. Toward understanding evidence uptake: semirecumbency for pneumonia prevention. Crit. Care Med., New York, v. 30, n. 7, p. 1472-7, 2002.

CRAVEN, D. E.; STEGER, K. A. Epidemiology of Nosocomial Pneumonia : New Perspectives on an Old Disease. Chest, Chicago, v. 108, n. 2, p. 1-16, 1995. Suplemento 2.

DAVID, C. M. N. Infecção em UTI. Medicina, Ribeirão Preto, v. 31, p. 337-48, jul./set. 1998.

DODEK, P. et al. Evidence-based clinical practice guideline for the prevention of ventilator-associated pneumonia. Ann. Intern. Med., Philadelphia, v. 141, n. 4, p. 305-13, ago. 2004.

DONABEDIAN, A. La calidad de la atención médica: definición y métodos de evaluación. Tradução Carolina Amor de Fournier. México: La Prensa Médica Mexicana, 1984.

. The seven pillars of quality. Arch. Pathol. Lab. Med., Chicago, v. 114, p. 1115-8, 1990.

Striving for quality in health care. An inquiry into Police and practice. Chicago: Health Administration Press, 1991.

Evalución de la calidad de la atención médica. In: WHITE, K. L.; FRANK, J. (Org.). Investigaciones sobre servicios de salud: una antologia. Washington, DC: OPAS, 1992a. p. 382-404.

. The role of outcomes in quality assessment and assurance. QRB Qual. Rev. Bull., v. 18, p. 356-360, 1992b. 
DRAKULOVIC, M. B. et al. Supine body position as a risk factor for nosocomial pneumonia in mechanically ventilated patients: a randomised trial. Lancet, London, v. 354, n. 9193, p. 1851-58, Nov. 1999.

DREYER, E. Definição operacional da qualidade da assistência de enfermagem em unidade de terapia intensiva de um hospital-escola. Rev. Bras. Enferm., Brasília, DF, v. 50, n. 2, p. 229-46, abr./jun. 1997.

FERNANDES, A. T.; FERNANDES, M. O. V.; RIBEIRO FILHO, N. Infecção hospitalar e suas interfaces na área da saúde. São Paulo: Atheneu, 2000. v. 1.

FERNANDES, J. D. et al. Qualidade do gerenciamento como tecnología do cuidar. Texto Contexto Enferm., Florianópolis, v. 9, n. 1, p. 153-176, jan./abr. 2000.

FONSECA, A. S. et al. Auditoria e o uso de indicadores assistenciais: uma relação mais que necessária para a gestão assistencial na atividade hospitalar. Mundo Saúde, São Paulo, v. 29, n. 2, p. 161-9, abr./jun. 2005.

FUNDAÇÃO NACIONAL DA QUALIDADE (FNQ). Rede Nacional da Gestão Rumo à Excelência. Critérios para avaliação do desempenho e diagnóstico organizacional. Prêmio Nacional da Gestão em Saúde (ciclo 2006-2007). 2006. São Paulo: FNQ/CQH. Disponível em: http://www.fnq.org.br/Portals/ FNQ/Documents/RE2006\%20Rev3 final.pdf. Acesso em: 12 fev. 2010. .

GASPAR, G. G.; RODRIGUES, F. B. Etiopatogenia das infecções hospitalares. In: COSTA, J. C. Infecção hospitalar: aspectos básicos. 2009. Disponível em: http://intranet.hcrp.fmrp.usp.br/intranet/intranet.download.aspx. Acesso em: 17 ago. 2009.

GEORGE, D. L. et al. Epidemiology of Ventilator-acquired Pneumonia Based on Protected Bronchoscopic Sampling. Am. J. Respir. Crit. Care Med., New York, v. 158, n. 6, p. 1839-47, dec., 1998.

GRAP, M. J.; MUNRO, C. L. Ventilator-associated pneumonia: clinical significance and implications for nursing. Heart Lung, St Louis, v. 26, n. 6, p. 419-29, 1997.

GUSMÃO, M. E. N.; DOURADO, I.; FIACCONE, R. L. Nosocomial pneumonia in the intensive care unit of a Brazilian university hospital: an analysis of the time span from admission to disease onset. Am. J. Infect. Control., S. Louis, v. 32, n. 4, p. 209-14, Jun. 2004. 
GUIMARÃES, M. M. Q.; ROCCO, J. R. Prevalence of ventilator-associated pneumonia in a university hospital and prognosis for the patients affected. J. Bras. Pneumol., Brasília, DF, v. 32, n. 4, p. 339-46, 2006.

HADDAD, M. C. L. Qualidade da assistência de enfermagem: o processo de avaliação em um hospital universitário público. 2004. 201 f. Tese (Doutorado em Enfermagem Fundamental) - Escola de Enfermagem de Ribeirão Preto, Universidade de São Paulo, Ribeirão Preto, 2004.

IANKOVA, A. The Glasgow coma scale clinical application in emergency departament. Emerg. Nurse, v. 14, n. 8, p. 30-35, 2006.

JERRE, G. et al. III Consenso Brasileiro de Ventilação Mecânica. Fisioterapia no paciente sob ventilação mecânica. J. Bras. Pneumol., Brasília, DF, v. 33, p. S142S150, 2007. Suplemento 2.

JOINT COMISSION ON ACREDITATION OF HEALTHCARE ORGANIZATION (JCAHO). List of Joint Comission Approved Subjects for Screening Indicators for Hospital. 2006. Disponível em: http://www.jointcomission.org. Acesso em: 31 maio 2006.

KREIN, S. L. et al. Preventing ventilator-associated pneumonia in the United States: A multicenter mixed-methods study. Infect. Control Hosp. Epidemiol., Thorofare, v. 29 , n. 10, p. 933-40, ago. 2008.

KURCGANT, P.; TRONCHIN, D. M. R.; MELLEIRO, M. M. A construção de indicadores de qualidade para a avaliação de recursos humanos nos serviços de enfermagem: pressupostos teóricos. Acta Paul. Enferm., São Paulo, v. 19, n. 1, p. 88-91, 2006.

LACERDA, R. A.; JOUCLAS, V. M. G.; ENGRY, E. Y. A face iatrogênica do hospital. As demandas para o controle de infecção hospitalar. São Paulo: Atheneu, 1996.

LAUS, A. M. Dimensionamento de pessoal de enfermagem para unidades médicas e cirúrgicas no Hospital das Clínicas da Faculdade de Medicina de Ribeirão Preto-USP. 2003. 212 f. Tese (Doutorado) - Escola de Enfermagem de Ribeirão Preto, Universidade de São Paulo, Ribeirão Preto, 2003.

LODE, H. Nosocomial pneumonia: epidemiology, pathogenesis, diagnosis, treatment and prevention. Curr Opin Infect Dis, v. 13, n. 4, p. 377-84, aug., 2000.

MALIK, A. M. Avaliação, qualidade, gestão.... para trabalhadores da área de saúde e outros interessados. São Paulo: SENAC, 1996. 
Pesquisa em, sobre e para os serviços de saúde: comentários em relação à pesquisa sobre serviços de saúde no Brasil. Cad. Saúde Pública, Rio de Janeiro, v. 20, p. 161-3, 2004. Suplemento 2.

MATSUDA, L. M.; ÉVORA, Y. D. M.; BOAN, F. S. O foco no cliente no processo de atendimento de enfermagem: visão dos enfermeiros. Nursing, São Paulo, v. 3, n. 29 , p. $16-20$, out. 2000.

MEDEIROS, E. A. S. Pneumonias hospitalares: aspectos epidemiológicos e prevenção. Compacta Infect., São Paulo, v. 2, p. 15-22, 1992.

MENEZES, I. R. S. C. Avaliação da conformidade de práticas de controle e prevenção da pneumonia associada à ventilação mecânica em um hospital público de ensino. 2009. 164 f. Dissertação (Mestrado) - Escola de Enfermagem, Universidade de São Paulo, São Paulo, 2009.

MIGUEL-ROIG, C. et al. Cuidados de enfermería en la prevención de la neumonía asociada a ventilación mecánica. Revisión sistemática. Enferm. Clín., Barcelona, v. 16, n. 5, p. 245-54, 2006. Disponível em: <http://www.dayama.es>. Acesso em: 03 Set. 2007.

MOURA, M. E. B et al. Infecção hospitalar: estudo de prevalência em um hospital público de ensino. Rev. Bras. Enferm., Brasília, DF, v. 60, n. 4, ago. 2007. Disponível em: http://www.scielo.br/scielo.php?script=sci arttext\&pid=S003471672007000400011\&lng=en\&nrm=iso . Accesso em: 16 jun. 2010.

MOURA, E. C. As sete ferramentas gerenciais da qualidade: implementando a melhoria contínua com maior eficácia. São Paulo: Makcron Books, 2000.

MONTE, A. D. A. S.; ADAMI, N. P.; BARROS, A. L. B. L. Métodos avaliativos da assistência de enfermagem em instituições hospitalares. Acta Paul. Enferm., São Paulo, v. 14, n. 1, p. 89-97, 2001.

MOTA, N. V. V. P.; MELLEIRO, M. M.; TRONCHIN, D. M. R. A construção de indicadores de qualidade de enfermagem: relato de experiência do Programa de Qualidade Hospitalar. RAS, São Paulo, v. 9, n. 34, p. 9-15, jan./mar. 2007.

NONINO, E.A.P.M. Avaliação da qualidade dos procedimentos de enfermagem - banho e curativo - segundo o grau de dependência assistencial dos pacientes internados em um hospital universitário. 2006. $242 \mathrm{f}$. Tese (Doutorado em Enfermagem) - Escola de Enfermagem de Ribeirão Preto, Universidade de São Paulo, Ribeirão Preto, 2006. 
NTOUMENOPOULOS, G. et al. Chest physiotherapy for the prevention of ventilatorassociated pneumonia. Intensive Care Med., New York, v. 28, n. 7, p. 850-6, Jul. 2002.

NOVAES, H. M. D. Avaliação de programas, serviços e tecnologias em saúde. Rev. Saúde Pública, São Paulo, v. 34, n. 5, p. 547-59, out. 2000.

ORGANIZAÇÃO MUNDIAL DA SAÚDE (OMS). Avaliação dos programas de saúde: normas para sua aplicação no processo de gestão para o desenvolvimento nacional da saúde. Genebra, 1981.

PADILHA, K. G.; KIMURA, M. Aspectos éticos da prática de enfermagem em Unidade de Terapia Intensiva. Sobeti Rev., São Paulo, v. 1, n. 1, p. 8-11, mar. 2000.

PAIVA, S. M. A qualidade da assistência hospitalar: avaliação dos usuários durante seu período de internação. 2006. 165 f. Tese (Doutorado em Enfermagem) Escola de Enfermagem de Ribeirão Preto, Universidade de São Paulo, Ribeirão Preto, 2006.

PERROCA, M. G.; GAIDZINSKI, R. R. Análise da validação de constructo do instrumento de classificação de pacientes proposto por Perroca. Rev. Latino-am. Enferm., Ribeirão Preto, v. 12, n. 1, p. 83-91, fev. 2004.

POLIT, D.; BECK, C. T.; HUNGLER, B. P. Fundamentos de pesquisa em enfermagem: métodos, avaliação e utilização. 5. ed. Porto Alegre: Artmed, 2004.

POSNER, J. et al. Plum and Posner's diagnosis of stupor and coma. New York: Oxfod University Press, 2007.

PRADE, S. S. et al. Estudo brasileiro da magnitude das infecções hospitalares em hospitais terciários. Rev. Controle Infec. Hosp., Brasília, DF, v. 2, p. 11-24, 1995.

RÊGO, M. M. S.; PORTO, I. S. Implantação de sistemas de qualidade em instituições hospitalares: implicações para enfermagem. Acta Paul. Enferm., São Paulo, v. 18, n. 4, p. 434-8, 2005.

RELLO, J. et al. Epidemiology and outcomes of ventilator-associated pneumonia in a large US database. Chest, Chicago, v. 122, n. 6, p. 2115-21, 2002.

RICART, M. et al. Nursing adherence with evidence-based guidelines for preventing ventilator-associated pneumonia. Crit. Care Med., New York, v. 31, n. 11, p. 2693-6, 2003. 
RODRIGUES, F. B. Uso de solução oral de clorexedina para prevenção de infecções respiratórias nosocomiais em terapia intensiva. 2009. 115 f. Tese (Doutorado em Clínica Médica) - Faculdade de Medicina de Ribeirão Preto, Universidade de São Paulo, Ribeirão Preto, 2009.

SÃO PAULO (Estado). Secretaria da Saúde. Divisão de Infecção Hospitalar. Centro de Vigilância Epidemiológica. Controle e Prevenção de Infecção Respiratória. Manual de indicadores de avaliação da qualidade de práticas de controle de infecção hospitalar. São Paulo, 2006. Disponível em: http://www.cve.saude.sp.gov.br/htm/ih/lH MANUALFAPESP06.pdf. Acesso em: 16 set. 2009.

SALOMÃO, R. et al. Device-associated infection rates in intensive care units of Brasilian hospital: findings of the International Nosocomial Infection Control Consortium. Rev. Panam. Salud. Publica, Washington, DC, v. 24, n. 3, p. 195-202, 2008.

SILVA, L. M.; FORMIGLI, V. L. A. Avaliação em saúde: limites e perspectivas. Cad. Saúde Pública, Rio de Janeiro, v. 10, n. 1, p. 80-91, jan./mar. 1994.

SILVA, M. J. P.; PINHEIRO, E. M. Qualidade na assistência de enfermagem - visão de alunas de especialização. Acta Paul. Enferm., São Paulo, v. 14, n. 1, p. 82-8, 2001.

SILVA, S. H. Controle da qualidade assistencial em enfermagem: implementação de um modelo. 1994. 182 f. Tese (Doutorado em Enfermagem) - Escola de Enfermagem, Universidade de São Paulo, São Paulo, 1994.

SENTONE, A. D. D. Análise dos indicadores da qualidade na elaboração da prescrição de enfermagem em uma unidade de internação de um hospital universitário público. 2005. 110 f. Dissertação (Mestrado em Enfermagem) Escola de Enfermagem de Ribeirão Preto, Universidade de São Paulo, Ribeirão Preto, 2005.

SOCIEDADE BRASILEIRA DE PNEUMOLOGIA E TISIOLOGIA (SBPT). Diretrizes brasileiras para tratamento das pneumonias adquiridas no hospital e das associadas à ventilação mecânica. J. Bras. Pneumol., Brasília, DF, v. 33, p. 1-30, 2007. Suplemento $1 . \quad$ Disponível em: $<$ http://www.scielo.br/scielo.php?script=sci arttext\&pid=51806-

37132007000700001\&lng=pt\&nrm=iso>. Acesso em: 20 set. 2007.

SOUZA, F. S. L. Indicadores da qualidade em enfermagem na síndrome coronariana aguda. 2006. 113 f. Dissertação (Mestrado) - Escola de Enfermagem Anna Nery, Universidade Federal do Rio de Janeiro, Rio de Janeiro, 2006. 
STAVALE, M. A. Bases para terapia intensiva neurológica. São Paulo: Manole, 1996.

TABLAN, O. C. et al. Guidelines for preventing health-care--associated pneumonia, 2003. Recommendations of Centers for Disease Control and Prevention and the Healthcare Infection Control Practices Advisory Committee. MMWR., Atlanta, v. 53, n. 3, p. 1-36, mar. 2004. Disponível em: http://www.cdc.gov/mmwr/preview/mmwrhtml/rr530321.htm. Acesso em: 21 maio 2007.

TEIXEIRA, J. D. R. et al. A elaboração de indicadores de qualidade da assistência de enfermagem nos períodos puerperal e neonatal. Rev. Enferm. UERJ, Rio de Janeiro, v. 14, n. 2, p. 271-8, abr./jun. 2006.

TEIXEIRA, P. J. Z. et al. Pneumonia associada à ventilação mecânica: impacto da multirresistência bacteriana na morbidade e mortalidade. J. Bras. Pneumol., Brasília, DF, v. 30, n. 6, p. 540-8, 2004.

VAN NIEUWENHOVEN, C. A. et al. Feasibility and effects of the semirecumbent position to prevent ventilator-associated pneumonia: a randomized study. Crit. Care Med., New York, v. 34, n. 2, p. 396-402, 2006.

VUORI, H. A qualidade da saúde. Divulg. Saúde Debate, Londrina, n. 3, p. 17-25, 1991.

WHITMAN, G. R. et al. Measuring nurse-sensitive patient outcomes across specialty units. Outcomes Manag., Hagerstown, v. 6, n. 4, p. 152-8, 2002.

ZANON, U. Qualidade da assistência médico-hospitalar: conceito, avaliação e discussão dos indicadores de qualidade. Rio de Janeiro: Medsi, 2001.

ZEITOUN, S. S. et al. Incidência de pneumonia associada à ventilação mecânica em pacientes submetidos à aspiração endotraqueal pelos sistemas aberto e fechado: estudo prospectivo - dados preliminares. Rev. Latino-am. Enferm., Ribeirão Preto, v. 9, n. 1, p. 46-52, jan. 2001. 
92

Apêndices 


\section{APÊNDICE A}

\section{Dados Demográficos e Clínicos de Caracterização de Pacientes}

\begin{tabular}{|c|l|l|l|c|c|c|c|c|c|}
\hline Paciente & Registro & Idade & Sexo & $\begin{array}{c}\text { Unidade } \\
\text { Prévia de } \\
\text { Internação }\end{array}$ & $\begin{array}{c}\text { Tempo de } \\
\text { Internação } \\
\text { Anterior } \\
\text { à UTI }\end{array}$ & $\begin{array}{c}\text { Tempo de } \\
\text { Internação } \\
\text { na UTI }\end{array}$ & $\begin{array}{c}\text { Apache } \\
\text { II }\end{array}$ & $\begin{array}{c}\text { Desenvolvimento } \\
\text { PNM }\end{array}$ & Desfecho \\
\hline 1 & & & & & & & & & \\
\hline 2 & & & & & & & & & \\
\hline 3 & & & & & & & & & \\
\hline 4 & & & & & & & & & \\
\hline $\mathrm{n}$ & & & & & & & & & \\
\hline
\end{tabular}




\section{APÊNDICE B}

\section{Planilha de Avaliação Diária Modificada}

Paciente*:

Leito:

\begin{tabular}{|c|c|c|c|c|c|c|c|c|c|c|c|c|c|}
\hline \multirow[t]{3}{*}{ Evidéncia } & \multirow{2}{*}{\multicolumn{2}{|c|}{$\begin{array}{c}\text { A } \\
\text { Utilizada } \\
\text { soluções estéreis } \\
\text { para } \\
\text { nebulizadores e } \\
\text { umidificadores** }\end{array}$}} & \multirow{2}{*}{\multicolumn{2}{|c|}{$\begin{array}{c}\text { C } \\
\text { Circuito de } \\
\text { terapia } \\
\text { inalatória } \\
\text { em uso e } \\
\text { respeitando } \\
\text { rotina de } \\
\text { troca*** }\end{array}$}} & & C & & & C & & \multirow{2}{*}{\multicolumn{2}{|c|}{ Conclusão }} & \multirow{3}{*}{$\begin{array}{l}\text { Condições } \\
\text { presentes }\end{array}$} \\
\hline & & & & & \multicolumn{3}{|c|}{$\begin{array}{c}\text { Atendimento } \\
\text { diário de } \\
\text { fisioterapia**** }\end{array}$} & \multicolumn{3}{|c|}{$\begin{array}{l}\text { Cabeceira } \\
\text { elevada 30- } \\
45^{\circ} \text { (VM, } \\
\text { coma ou } \\
\text { sedação) }\end{array}$} & & & \\
\hline & A & NA & $A$ & NA & A & NA & SA & $A$ & NA & SA & Conf. & $\begin{array}{l}\text { Não } \\
\text { Conf. }\end{array}$ & \\
\hline $\begin{array}{r}\mathrm{M} \\
\mathrm{T} \\
\mathrm{N}\end{array}$ & & & & & & & & & & & & & $\begin{array}{c}\text { VM } \\
\downarrow \text { consciência } \\
\text { SNG/SNE }\end{array}$ \\
\hline $\begin{array}{r}\mathrm{M} \\
\mathrm{T} \\
\mathrm{N}\end{array}$ & & & & & & & & & & & & & $\begin{array}{c}\text { VM } \\
\downarrow \text { consciência } \\
\text { SNG/SNE }\end{array}$ \\
\hline $\begin{array}{l}M \\
T \\
N\end{array}$ & & & & & & & & & & & & & $\begin{array}{c}\text { VM } \\
\downarrow \text { consciência } \\
\text { SNG/SNE }\end{array}$ \\
\hline $\begin{array}{l}\mathrm{M} \\
\mathrm{T} \\
\mathrm{N}\end{array}$ & & & & & & & & & & & & & $\begin{array}{c}\text { VM } \\
\downarrow \text { consciência } \\
\text { SNG/SNE }\end{array}$ \\
\hline $\begin{array}{l}\mathrm{M} \\
\mathrm{T} \\
\mathrm{N}\end{array}$ & & & & & & & & & & & & & $\begin{array}{c}\text { VM } \\
\downarrow \text { consciência } \\
\text { SNG/SNE }\end{array}$ \\
\hline
\end{tabular}

Observações: A - Atende

SA - Sem aplicação

*Avaliar apenas pacientes sob assistência ventilatória, com rebaixamento de consciência e/ou nutrição por sondas digestivas.

**Observação direta, em balcões, mesa de cabeceira ou de procedimento, da existência de frascos de água destilada abertos ou seringas com SF. Considera-se ATENDE quando não forem encontrados frascos de água destilada abertos ou seringas com SF.

${ }^{* * *}$ Avaliação direta (caso rotina preconize datar o material) ou avaliação indireta através do prontuário (prescrição de enfermagem ou fisioterapia com registro das trocas).

****Avaliação deve ser feita através do prontuário (nos dias anteriores à auditoria). 


\section{APÊNDICE C}

\section{Termo de Consentimento Livre e Esclarecido}

\section{ESCLARECIMENTOS AOS RESPONSÁVEIS PELOS SUJEITOS DA PESQUISA}

Estamos realizando uma pesquisa no Hospital das Clínicas da Faculdade de Medicina de Ribeirão Preto - USP, cujo título é "AVALIAÇÃO DA QUALIDADE DA ASSISTÊNCIA DE ENFERMAGEM QUANTO ÀS MEDIDAS DE PREVENÇÃO E CONTROLE DE PNEUMONIA ASSOCIADA À VENTILAÇÃO MECÂNICA". O objetivo da pesquisa é avaliar a qualidade da assistência de enfermagem prestada aos pacientes que se encontram respirando com ajuda de aparelhos (em ventilação mecânica) na Unidade de Terapia Intensiva deste Hospital, quanto às medidas adotadas de prevenção e controle de pneumonia.

Para tanto necessitamos realizar uma observação direta dos pacientes que estão em ventilação mecânica, nos seguintes itens: utilização de soluções estéreis para nebulizadores e umidificadores; circuito de terapia inalatória em uso e respeitando rotina de troca; atendimento diário de fisioterapia respiratória; e cabeceira elevada $30-40^{\circ}$ durante o período de internação nesta unidade.

Além disso, alguns dados como idade, sexo e data da internação serão coletados dos prontuários. As informações obtidas com a pesquisa poderão ser úteis para rever os procedimentos técnicos realizados pela equipe de saúde e contribuir com a elaboração de programas de educação em serviço.

Deste modo, gostaríamos de convidar o sr.(a) a participar desta pesquisa, reforçando que sua colaboração é muito importante.

Assim, solicitamos sua AUTORIZAÇÃO, considerando a impossibilidade do sr.(a) decidir por si próprio em razão de

suas condições de saúde, para coletar os dados relativos ao seu familiar, colaborando, assim, com a realização deste estudo. Comprometemo-nos a garantir o sigilo e a privacidade dos dados obtidos, bem como o anonimato dos participantes do estudo.

A participação será voluntária e o sr.(a) poderá retirar seu consentimento ou desistir desta participação em qualquer fase da pesquisa, sem penalização alguma e nem prejuízo ao cuidado dispensado a seu familiar, se assim o desejar.

Declaramos, ainda, que os resultados da pesquisa serão tornados públicos, sejam eles favoráveis ou não.

AUTORIZO

Leandra Terezinha Roncolato da Silva

Pesquisadora

Unidade de Emergência do HCRP-USP

Rua Bernardino de Campos, 1000

Higienópolis

Fone: (16)36021198
Prof $^{\mathrm{a}} \mathrm{Dr}^{\mathrm{a}}$ Ana Maria Laus Orientadora

Escola de Enfermagem de Ribeirão Preto-USP Avenida dos Bandeirantes, 3900

Campus Universitário

Fone: (16)36023433 
Anexos 


\section{ANEXO A \\ Cópia Aprovação do CEP}

HOSPITAL DAS CLÍNICAS DA FACULDADE DE MEDICINA DE RIBEIRĀO PRETO DA UNIVERSIDADE DE SÄO PAULO

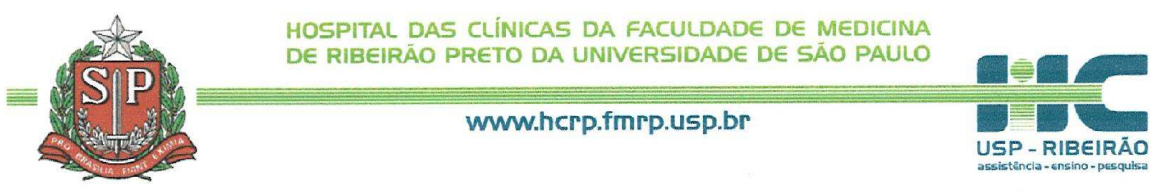

Ribeirão Preto, 03 de março de 2009.

Oficio $n^{\circ} 643 / 2009$

$\mathrm{CEP} / \mathrm{MGV}$

\section{Prezadas Senhoras,}

O trabalho intitulado "AVALIAÇÃO DA QUALIDADE DA ASSISTÊNCIA DE ENFERMAGEM QUANTO Às MEDIDAS DE PREVENÇÃO E CONTROLE DE PNEUMONIA ASSOCIADA À VENTILAÇÃo MECÂNICA" foi analisado pelo Comitê de Ética em Pesquisa, em sua $281^{a}$ Reunião Ordinária, realizada em 02/03/2009 e enquadrado na categoria: APROVADO, bem como o Termo de Consentimento Livre e Esclarecido, de acordo com o Processo HCRP n. 11193/2008.

Este Comitê segue integralmente a Conferência Internacional de Harmonização de Boas Práticas Clinicas (IGH-GCP), bem como a Resolução $n^{\circ}$. 196/96 CNS/MS.

Lembramos que devem ser apresentados a este CEP, o Relatório Parcial e o Relatório Final da pesquisa. Atenciosamente,

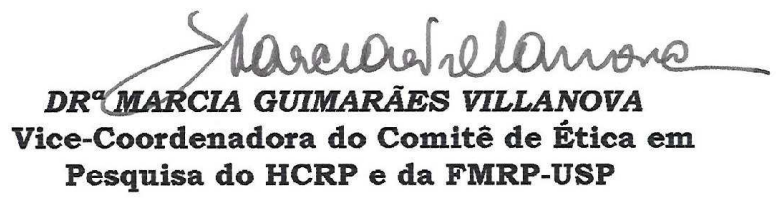

Ilustrissimas Senhoras

LEANDRA TEREZINHA RONCOLATO DA SILVA

PROF $^{\text {a DR }}$ aNA MARIA LAUS (ORIENTADORA)

ESCOLA DE ENFERMAGEM DE RIBEIRÃO PRETO-USP
Comitê de Ética em Pesquisa HCRP e FMRP-USP - Campus Universitário
FWA - 0000 2733; IRB - 00002186 e Registro SISNEP/CONEP n ${ }^{\circ} 4$
Fone (16) 3602-2228 - E-mail : cep@hcrp.fmrp.usp.br
Monte Alegre 14048-900 Ribeiräo Preto SP




\section{ANEXO B \\ Planilha de Avaliação Diária Original}

\begin{tabular}{|c|c|c|c|c|c|c|c|c|c|c|c|c|}
\hline Evidência & & & & & & C & & & C & & & \\
\hline \multirow[t]{2}{*}{ Pacientes* } & \multicolumn{2}{|c|}{$\begin{array}{c}\text { Utilizada } \\
\text { soluções estéreis } \\
\text { para } \\
\text { nebulizadores e } \\
\text { umidificadores }^{* *}\end{array}$} & \multicolumn{2}{|c|}{$\begin{array}{l}\text { Circuito de } \\
\text { terapia } \\
\text { inalatória em } \\
\text { uso e } \\
\text { respeitando } \\
\text { rotina de troca } \\
\text { estabelecida*** }\end{array}$} & \multicolumn{3}{|c|}{$\begin{array}{l}\text { Atendimento } \\
\text { diário de } \\
\text { fisioterapia } \\
\text { respiratória**** }\end{array}$} & \multicolumn{3}{|c|}{$\begin{array}{c}\text { Cabeceira } \\
\text { elevada 30- } \\
40^{\circ} . \text { (VM, } \\
\text { coma ou } \\
\text { sedação). }\end{array}$} & \multicolumn{2}{|c|}{ Conclusão } \\
\hline & A & NA & A & NA & A & NA & SA & A & NA & SA & Conf. & $\begin{array}{l}\text { Não } \\
\text { Conf. }\end{array}$ \\
\hline \multicolumn{13}{|l|}{1} \\
\hline \multicolumn{13}{|l|}{2} \\
\hline \multicolumn{13}{|l|}{3} \\
\hline \multicolumn{13}{|l|}{$\mathrm{N}$} \\
\hline Total & & & & & & & & & & & & \\
\hline
\end{tabular}

*Avaliar apenas pacientes sob assistência ventilatória, com rebaixamento de consciência e/ou nutrição por sondas digestivas.

**Observação direta, em balcões, mesa de cabeceira ou de procedimento, da existência de frascos de água destilada abertos ou seringas com SF. Considera-se ATENDE quando não forem encontrados frascos de água destilada abertos ou seringas com SF.

${ }^{* * *}$ Avaliação direta (caso rotina preconize datar o material) ou avaliação indireta através do prontuário (prescrição de enfermagem ou fisioterapia com registro das trocas).

${ }^{* \star * *}$ Avaliação deve ser feita através do prontuário (nos dias anteriores à auditoria). 